\title{
Xanthohumol inhibits PRRSV proliferation and alleviates oxidative stress induced by PRRSV via the Nrf2-HMOX1 axis
}

\author{
Xuewei Liu' ${ }^{1}$, Zhongbao Song ${ }^{1}$, Juan Bai ${ }^{1}$, Hans Nauwynck ${ }^{2}$, Yongxiang Zhao ${ }^{1}$ and Ping Jiang ${ }^{1,3^{*}}$
}

\begin{abstract}
Porcine reproductive and respiratory syndrome virus (PRRSV) is a prevalent and endemic swine pathogen that causes significant economic losses in the global swine industry. Commercial vaccines provide limited protection against this virus, and no highly effective therapeutic drugs are yet available. In this study, we first screened a library of 386 natural products and found that xanthohumol (Xn), a prenylated flavonoid found in hops, displayed high anti-PRRSV activity by inhibiting PRRSV adsorption onto and internalization into cells. Transcriptome sequencing revealed that Xn treatment stimulates genes associated with the antioxidant response in the nuclear factor-erythroid 2-related factor 2 (Nrf2) signalling pathway. Xn causes increased expression of Nrf2, HMOX1, GCLC, GCLM, and NQO1 in Marc-145 cells. The action of Xn against PRRSV proliferation depends on Nrf2 in Marc-145 cells and porcine alveolar macrophages (PAMs). This finding suggests that Xn significantly inhibits PRRSV proliferation and decreases viral-induced oxidative stress by activating the Nrf2-HMOX1 pathway. This information should be helpful for developing a novel prophylactic and therapeutic strategy against PRRSV infection.
\end{abstract}

\section{Introduction}

Porcine reproductive and respiratory syndrome (PRRS) is one of the most economically detrimental swine diseases worldwide. Infection is characterized by reproductive failure and preterm birth in sows as well as dyspnoea of piglets and fattening pigs $[1,2]$. The aetiologic agent is PRRS virus, a positive-sense, single-stranded RNA virus belonging to the family Arteriviridae in the order Nidovirales. PRRSV is divided into two genotypes, the European genotype (type I) and the North American genotype (type II), which share approximately $60 \%$ identity in amino acid sequences [3]. The mutation rate of PRRSV is $3.29 \times 10^{-3}$ substitutions per nucleotide site per year in China alone $[4,5]$. Commercially available vaccines can provide only incomplete protection. Modified live virus (MLV) vaccines protect against homologous strains [6],

\footnotetext{
${ }^{*}$ Correspondence: jiangp@njau.edu.cn

${ }^{1}$ Key Laboratory of Animal Disease Diagnostics and Immunology,

Ministry of Agriculture, MOE International Joint Collaborative Research Laboratory for Animal Health \& Food Safety, College of Veterinary

Medicine, Nanjing Agricultural University, Nanjing 210095, China Full list of author information is available at the end of the article
}

but they have the potential risk of reverting to a more virulent form or recombining with pandemic strains to form a novel genotype strain during serial passage in pigs [7]. These problems highlight the need for alternative approaches to control this disease. A combination of pharmacological intervention and vaccination is worthy of further inquiry.

The interaction between PRRSV and pigs has been well studied. Several host antiviral factors, such as the interferon-stimulated genes (ISGs) viperin [8], myxovirus resistance 2 (Mx2) [9], 2',5'-oligoadenylate synthetase 1 (OAS1) [10], interferon-induced protein with tetratricopeptide repeats 3 (IFIT3) [11], and $\mathrm{CH} 25 \mathrm{H}$ [12, 13], have been reported to have antiviral activity against PRRSV infection. Some microRNAs, small interfering RNAs (siRNAs) [14], and short-hairpin RNAs (shRNAs) [15] have also been shown to inhibit PRRSV replication. Meanwhile, some natural compounds and compositions have also been reported to have anti-PRRSV activity in vitro, such as sodium tanshinone IIA sulfonate [16], proanthocyanidin A2 [17], Griffithsin [18], and (-)-epigallocatechin-3-gallate [19]. However, the mechanism of 
antiviral activity is not deeply understood. In this study, we screened a library of 386 natural products and found that xanthohumol, a prenylated flavonoid extracted from the hop plant Humulus lupulus L, significantly inhibited the early stages of PRRSV infection and inhibited virally induced oxidative stress by activating the Nrf2-HMOX1 pathway in Marc-145 cells and PAMs, demonstrating excellent potential as a therapeutic agent.

\section{Materials and methods} Cells, viruses, and reagents

Marc-145 cells (an African green embryonic kidney epithelial cell line, ATCC) were cultured in Dulbecco's modified Eagle's medium (Invitrogen, USA) supplemented with $10 \%$ foetal bovine serum (FBS; GIBCO) at $37{ }^{\circ} \mathrm{C}$ in a humidified atmosphere containing $5 \% \mathrm{CO}_{2}$. Porcine alveolar macrophages (PAMs) were collected from lung lavages of 6-week-old Yorkshire pigs (free of PRRSV, PCV2, PRV), as previously described, and cultured in RPMI1640 (GIBCO) containing $10 \%$ FBS at $37^{\circ} \mathrm{C}$. Three North American genotype 2 PRRSV strains were employed. The highly pathogenic PRRSV strain BB0907 (GenBank accession no. HQ315835.1), which is maintained in our laboratory, was used for all experiments and is represented by "PRRSV" in this article. The PRRSV strains S1 (GenBank accession no. DQ459471.1) and FJ1402 (GenBank accession no. KX169191.1) were also used but are specifically mentioned by name ( $\mathrm{S} 1$, a classical strain; FJ1402, a NADC30-like strain).

Xanthohumol, purity $>99 \%$, was used for in vitro experiments (Selleck Chemicals, Houston TX, USA). Protoporphyrin IX cobalt chloride (CoPP), an inducer of HMOX1 expression, was purchased from Sigma (St. Louis, MO, USA).

\section{Screening of a natural product library}

A library of 386 natural products was purchased from Selleck Chemicals (Houston, TX, USA). These compounds were stored as $10 \mathrm{mM}$ stock solutions in DMSO at $80{ }^{\circ} \mathrm{C}$ until use. The workflow for screening the library is diagrammed in Figures 1A and B. Marc-145 cells were seeded in 96-well plates at $2 \times 10^{4}$ cells per well. When approximately $60 \%$ confluent, the cells were treated with $10 \mu \mathrm{M}$ compound or DMSO $(1 \mu \mathrm{L})$ for $1 \mathrm{~h}$ and then infected with PRRSV (0.01 MOI) or mock infected for $1 \mathrm{~h}$. Cells were then washed with PBS, and culture medium containing $10 \mu \mathrm{M}$ compound was added back to each well. At $48 \mathrm{~h}$ post-infection (hpi), the percentage of inhibition was calculated by CPE and IFA. For each assay, there were two technical replicates, i.e., two compoundinfected groups, two DMSO-PRRSV infected groups, and two DMSO-mock infected groups.
During the primary screening, compounds were screened out if they resulted in any observable cytotoxicity or demonstrated less than a $50 \%$ reduction of $\mathrm{CPE}$ compared with that of the DMSO control group. For the second round of screening, cell viability had to be $80 \%$ or greater, and the inhibition of PRRSV had to be $80 \%$ or greater $(0.01 \mathrm{MOI}$ and $0.1 \mathrm{MOI})$ via IFA. The $50 \%$ inhibitory concentration $\left(\mathrm{IC}_{50}\right)$ and $50 \%$ cytotoxic concentration $\left(\mathrm{CC}_{50}\right)$ of each remaining candidate compound were determined, and those that displayed dose-dependent inhibition of PRRSV and had a selectivity index greater than 10 were considered for further study.

\section{Cell viability assay}

Concentrations of Xn were added to cultures of Marc145 cells and incubated for $48 \mathrm{~h}$ at $37^{\circ} \mathrm{C}$. Cell viability was tested using a Cell Counting Kit-8 (CCK-8) (Beyotime, Nanjing, China) following the manufacturer's instructions. The $50 \%$ cytotoxic concentration $\left(\mathrm{CC}_{50}\right)$ was calculated using GraphPad Prism 7.0 software. DMSO was used as the negative control.

\section{PRRSV infectivity inhibition assay}

An indirect immunofluorescence assay (IFA) was used to examine the effect of Xn on PRRSV-infected Marc-145 cells. Two-fold serially diluted compounds were added to the culture medium of Marc-145 cells (final concentrations were $1 \mu \mathrm{M}$ to $20 \mu \mathrm{M}$ ). DMSO was used as the negative control. PRRSV (0.01 MOI) was then added onto the cells, and cultures were incubated for $48 \mathrm{~h}$ at $37{ }^{\circ} \mathrm{C}$. Cells were then fixed with $4 \%$ paraformaldehyde in PBS and permeabilized with $0.1 \%$ Triton X-100. After three washes with PBS, cells were incubated with an antiPRRSV N-protein mAb (made in our laboratory) [20] for $1 \mathrm{~h}$ at $37^{\circ} \mathrm{C}$. Cells were washed three times with PBS and then incubated with Alexa Fluor 594-conjugated goat anti-mouse IgG (H-L) (1:200, Proteintech) for $1 \mathrm{~h}$ at $37^{\circ} \mathrm{C}$ in the dark. Nuclei were stained with DAPI (Invitrogen, China) for $10 \mathrm{~min}$ at room temperature. Immunofluorescence was observed using a Nikon A1 confocal microscope (Nikon A1; Nikon, Japan). The level of fluorescence was determined using ImageJ software. GraphPad Prism 5.0 software was used to estimate the $50 \%$ inhibition concentration $\left(\mathrm{IC}_{50}\right)$ of each compound. The selectivity index (SI) was determined by the ratio of $\mathrm{CC}_{50}$ to $\mathrm{IC}_{50}$.

\section{Western blot assay}

Cells were lysed on ice for 15 min in lysis buffer (Beyotime, China), then resolved by SDS-PAGE and transferred to a nitrocellulose membrane. The membrane was blocked with 5\% low-fat milk for $2 \mathrm{~h}$ at room temperature and then probed with antibodies: anti-PRRSV N-protein (1:1000), anti- $\beta$-actin (1:1000; Santa Cruz, 
A
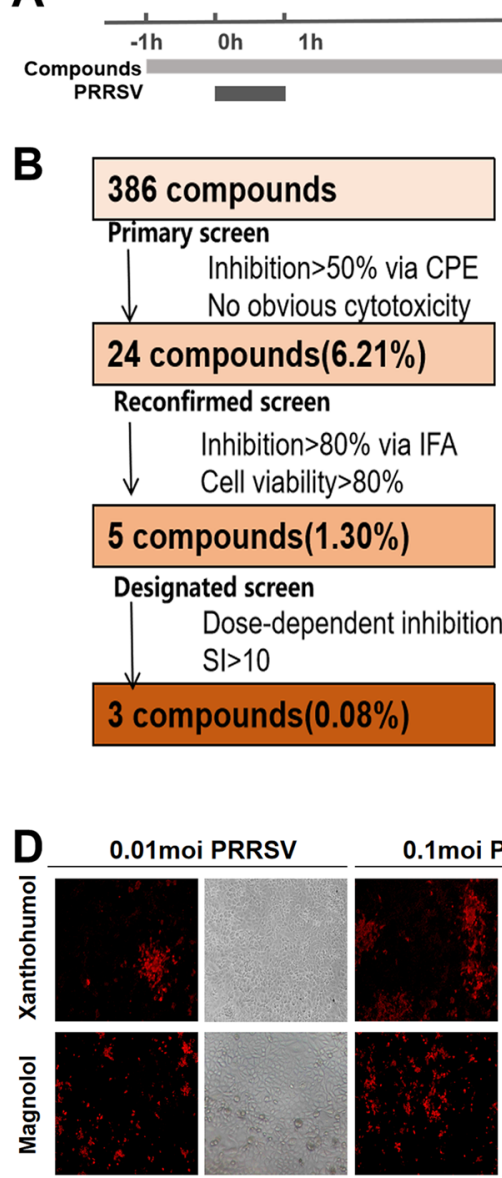

음
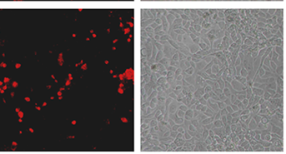

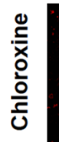
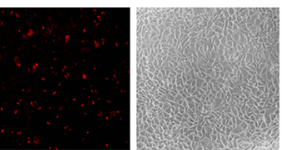

들
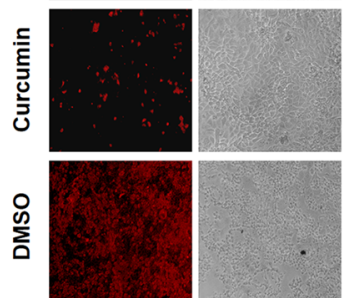

PRRSV-N

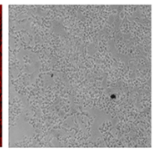

CPE
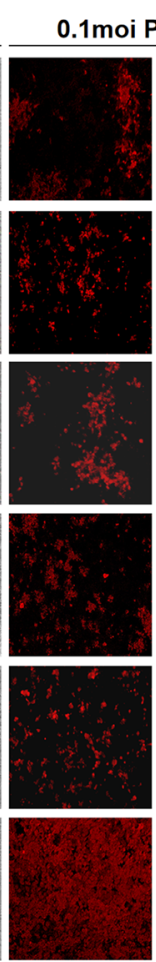

PRRSV-N
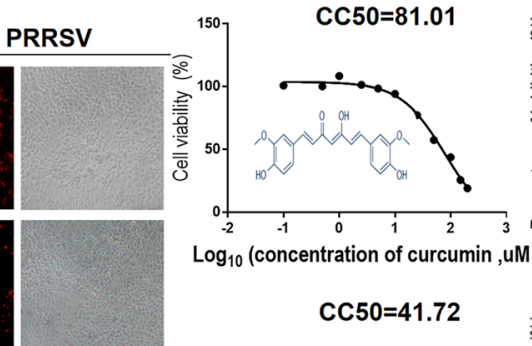

C

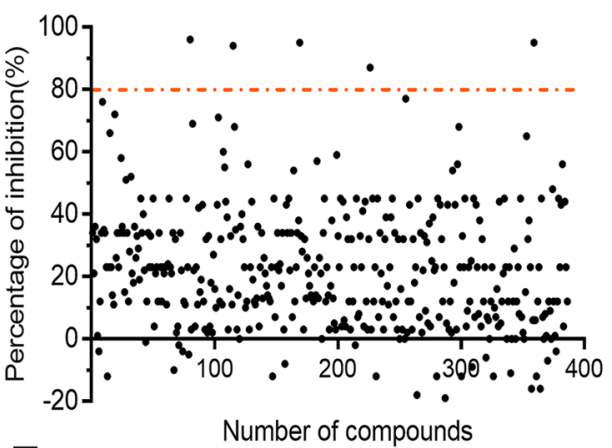

E

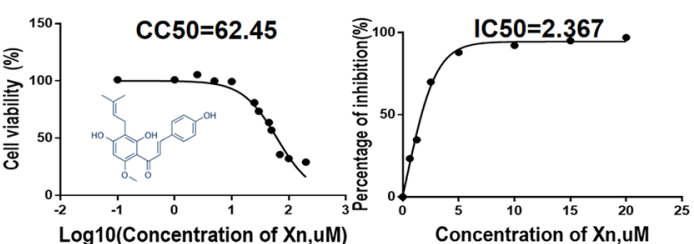

$\log _{10}$ (concentration of curcumin $u M$ )

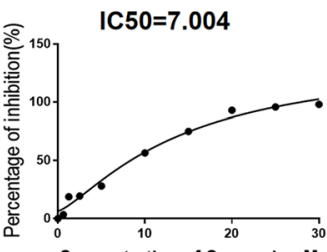

$\mathrm{CC} 50=41.72$

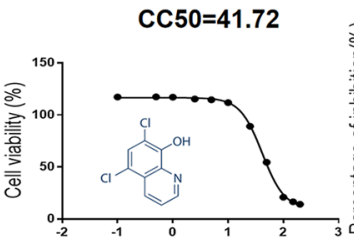

IC50=2.59
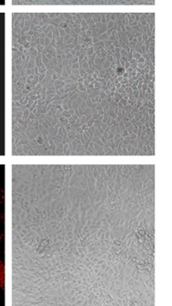

Log10 (concentration of Chloroxine, $\mu \mathrm{M}$ ) Concentration of Chloroxine, uM

$\mathbf{F}$

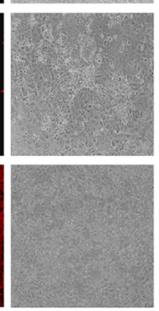

CPE

\begin{tabular}{cccc}
\hline Hit compunds & IC50(uM) & CC50(uM) & SI \\
\hline Xanthohumol & 2.37 & 62.45 & 26.38 \\
Nobiletin & 7.45 & 24.23 & 3.25 \\
Curcumin & 7.00 & 81.01 & 11.57 \\
Chloroxine & 2.59 & 41.72 & 16.10 \\
Magnolol & 6.34 & 14.34 & 2.26
\end{tabular}

Figure 1 Screening protocol for PRRSV inhibitors. A Screening procedure time course. Marc-145 cells were treated with $10 \mu \mathrm{M}$ compound for $1 \mathrm{~h}$ and then infected with PRRSV (0.01 MOI) for $1 \mathrm{~h}$. Cells were washed with PBS and then incubated in medium containing $10 \mu \mathrm{M}$ compound for another $48 \mathrm{~h}$. B Screening process flowchart. The criteria for passing the primary screen were that the compound had no apparent cytotoxicity and that it reduced CPE by at least 50\% compared with that of the positive controls. The criteria for passing the secondary screen were that the compound had to leave cells at least $80 \%$ viable and had to inhibit PRRSV (0.01 MOI and $0.1 \mathrm{MOI}$ ) by more than $80 \%$. Compounds that passed the tertiary screen inhibited PRRSV in a dose-dependent manner and had a selective index greater than ten. $\mathbf{C}$ Each dot represents the percent inhibition of PRRSV $(0.01 \mathrm{MOI})$ achieved with each compound. The dots located above the dotted line indicate $80 \%$ or greater inhibition. D IFA of infected cells treated with one of the five designated compounds. PRRSV N-protein is coloured red, and brightfield-imaged cells show $\mathrm{CPE} \mathbf{E} \mathrm{E}_{50}$ and $\mathrm{CC}_{50}$ curves of the 5 designated compounds. The structure of each compound is inset. F SIs of the 5 designated compounds. Selectivity index $(\mathrm{SI})=\mathrm{CC}_{50} / \mathrm{CC}_{50}$ 
CA, USA), anti-HMOX1 (1:1000; Proteintech, USA), and anti-human Nrf2 (1:1000; Proteintech) for $2 \mathrm{~h}$ at room temperature. Membranes were incubated with HRPconjugated goat anti-mouse and anti-rabbit $\operatorname{IgG}(\mathrm{H}-\mathrm{L})$ secondary antibodies (1:1000; Beyotime, China). Bound proteins were visualized with a Tanon 5200 chemiluminescence imaging system (Tanon, China).

\section{RNA extraction and quantitative real-time PCR}

Total RNA was extracted from cells using a Total RNA Kit I (Omega Bio-tek). RNA was then reverse transcribed using a HiScript II 1st Strand cDNA Synthesis Kit (Vazyme, China) following the manufacturer's instructions. Quantitative RT-PCR was performed using Ace ${ }^{\circledR}$ qPCR SYBR ${ }^{\circledR}$ Green Master Mix (Vazyme, China). Data are presented as the fold change in gene expression normalized to GAPDH and relative to the mock-infected control. Each reaction was performed in triplicate, and the data are calculated as the mean $(\mathrm{M}) \pm$ SEM. Primer sequences for genes are shown in Table 1.

\section{Virus titration}

Marc-145 cells grown in 96-well plates were infected with ten-fold serial dilutions of PRRSV. After $1 \mathrm{~h}$ at $37^{\circ} \mathrm{C}$, the culture medium was replaced with fresh DMEM- $2 \%$ FBS. Viral titres were determined using endpoint dilution analysis at 5 days post-inoculation (dpi). The ReedMuench method was used to calculate the $50 \%$ tissue culture infected dose $\left(\mathrm{TCID}_{50}\right)$.

\section{Time-of-addition experiment}

To evaluate which stage of the PRRSV life cycle is affected by Xn, a time-of-addition experiment was performed as shown in the timeline schematic (Figure 3A). Marc-145 cells seeded into 24-well plates were either pre-treated, co-treated, or post-treated with Xn relative to PRRSV inoculation. The experiment began when the cells reached $60 \%$ confluence and was noted as -1 h. At $0 \mathrm{~h}$, culture supernatants of the pre-treated cells were replaced by DMEM-2\% FBS, cells were then inoculated with PRRSV (0.01 MOI), the co-treated group was treated with $10 \mu \mathrm{M} \mathrm{Xn}$ and PRRSV, and the posttreated group was inoculated with PRRSV. At $+1 \mathrm{~h}$, the culture supernatants in the co- and post-treated groups were replaced with DMEM/2\% FBS, and the post-treated group was treated with $10 \mu \mathrm{M} \mathrm{Xn}$. Incubation of all groups continued for $48 \mathrm{~h}$.

\section{Virucidal activity assay}

A virucidal activity assay was performed to determine whether Xn interacts with PRRSV directly. Xn $(10 \mu \mathrm{M})$ or DMSO was incubated with PRRSV (0.001, 0.01, and 0.1 MOI) at $37^{\circ} \mathrm{C}$ for $2 \mathrm{~h}$. Marc- 145 cells in six-well plates
Table 1 Primer sequences of probes used for qPCR analysis

\begin{tabular}{|c|c|}
\hline Primer & Sequence $\left(5^{\prime} \rightarrow 3^{\prime}\right)$ \\
\hline mGAPDH-Fwd & 5' CCTTCCGTGTCCCTACTGCCAA $3^{\prime}$ \\
\hline mGAPDH-Rev & $5^{\prime}$ GACGCCTGCTTCACCACCTTCT $3^{\prime}$ \\
\hline mHMOX-1-Fwd & $5^{\prime}$ CTTCAAGCTGGTGATGGC $3^{\prime}$ \\
\hline mHMOX-1-Rev & 5'TGGAGCCGCTTCACATAG 3' \\
\hline mNrf2-Fwd & $5^{\prime}$ ATTCAATGATTCTGACTCTG $3^{\prime}$ \\
\hline mNrf2-Rev & $5^{\prime}$ CGTATCCCCAGAAGAATGTA 3' \\
\hline mNQO1-Fwd & $5^{\prime}$ CATGTACTCTCTGCAAGGGA 3' \\
\hline mNQO1-Rev & 5' TCCCAAATATTCTCCAGGCG 3' \\
\hline mTXNRD1-Fwd & $5^{\prime}$ TGTTGTGGGCTTTCACGTAC 3' \\
\hline mTXNRD1-Rev & $5^{\prime}$ ATGTTGTGAATACCTCTGCA $3^{\prime}$ \\
\hline mTNXIP-Fwd & $5^{\prime}$ CGACCCTGAAAAGGTGTAC $3^{\prime}$ \\
\hline mTNXIP-Rev & $5^{\prime}$ CGAACTTGTACTCATATTTG $3^{\prime}$ \\
\hline mGCLM-Fwd & $5^{\prime}$ TCAGTGGGCACAGGTAAAA 3' \\
\hline mGCLM-Rev & $5^{\prime}$ TTGTTTAGCAAATGCAGTCA $3^{\prime}$ \\
\hline mGCLC-Fwd & 5' ACATGCGAAAACGGCGGAA 3' \\
\hline mGCLC-Rev & 5' CGAGGGTGCTTGTTTATTGC 3' \\
\hline pHMOX-1-Fwd & 5' GGCTGAGAATGCCGAGTT 3' \\
\hline pHMOX-1-Rev & $5^{\prime}$ ATGTAGCGGGTGTAGGCG 3' \\
\hline PRRSV-ORF7-Fwd & 5' AAACCAGTCCAGAGGCAAG 3' \\
\hline PRRSV-ORF7-Rev & $5^{\prime}$ TCAGTCGCAAGAGGGAAAT 3' \\
\hline
\end{tabular}

$\mathrm{p}$ means pig and $\mathrm{m}$ means monkey

were pre-cooled at $4{ }^{\circ} \mathrm{C}$ for $1 \mathrm{~h}$. The culture supernatants were replaced with a mixture of $\mathrm{Xn}(10 \mu \mathrm{M})$ or DMSO and PRRSV. After incubation at $4{ }^{\circ} \mathrm{C}$ for another $1 \mathrm{~h}$, cells were overlaid with DMEM containing 1\% low-meltingpoint agarose (Sigma-Aldrich) and 2\% FBS and incubated for $72 \mathrm{~h}$ at $37^{\circ} \mathrm{C}$. The cells were overlaid with $1 \%$ crystal violet in methanol and incubated for an additional $2 \mathrm{~h}$ at $37^{\circ} \mathrm{C}$. Plaque-forming units were counted.

\section{Virus adsorption assay}

Marc-145 cells cultured in 24-well plates were pre-chilled at $4{ }^{\circ} \mathrm{C}$ for $1 \mathrm{~h}$. Culture supernatants were then replaced by a $4{ }^{\circ} \mathrm{C}$ mixture of $\mathrm{Xn}(5,10$, and $15 \mu \mathrm{M})$ or DMSO and PRRSV (1 MOI) and incubated at $4{ }^{\circ} \mathrm{C}$ for another $1 \mathrm{~h}$. Cells were washed with ice-cold PBS, and then the mRNA levels of PRRSV ORF7 in cells were measured using qRT-PCR.

\section{Virus internalization assay}

Marc-145 cells were plated, grown to approximately $70 \%$ confluence, pre-treated with cycloheximide (CHX) $(10 \mu \mathrm{g} / \mathrm{mL})$ for $12 \mathrm{~h}$, washed and incubated with PRRSV (1 MOI) for $1 \mathrm{~h}$ at $4{ }^{\circ} \mathrm{C}$ to allow virus attachment. Cells were washed 3 times with ice-cold PBS to remove unbound virus. Then, the culture medium was replaced 
with fresh DMEM containing $10 \mu \mathrm{M}$ Xn or DMSO, and the cells were incubated for $2 \mathrm{~h}$ at $37^{\circ} \mathrm{C}$. Cells were washed with citrate buffer $(\mathrm{pH} 3)$ to remove non-internalized virus. The levels of PRRSV ORF7 mRNA were detected by qRT-PCR, and the virions in cells were detected and visualized using IFA confocal laser-scanning microscopy.

\section{Virus replication assay}

Marc-145 cells were incubated with PRRSV (1 MOI) at $37{ }^{\circ} \mathrm{C}$. At $6 \mathrm{hpi}$, cells were washed 3 times with PBS to remove free virus, the culture medium was replaced with fresh DMEM-2\% FBS containing Xn $(10 \mu \mathrm{M})$ or DMSO, and the cultures were incubated at $37{ }^{\circ} \mathrm{C}$. At 7,8 , 9, and $10 \mathrm{hpi}$, PRRSV genome levels in cells were measured using qRT-PCR.

\section{Virus release assay}

Marc-145 cells were infected with PRRSV (0.1 MOI) for $1 \mathrm{~h}$ at $37{ }^{\circ} \mathrm{C}$, and the culture medium was then replaced with fresh DMEM-2\% FBS. At $24 \mathrm{hpi}$, the cells were washed 3 times with $\mathrm{PBS}$, the culture medium was replaced with fresh DMEM-2\% FBS containing Xn $(10 \mu \mathrm{M})$ or DMSO, and the cultures were incubated at $37{ }^{\circ} \mathrm{C}$ for 10,30 , and $60 \mathrm{~min}$, at which point the supernatants were harvested. Released virus was quantified by plaque assay.

\section{RNA isolation, sequencing, and functional analysis}

Marc-145 cells exposed to $10 \mu \mathrm{M}$ Xn or DMSO for 4 , 8 , and $12 \mathrm{~h}$ were collected for transcriptomic analysis; for each time point, there were two biological replicates. RNA isolation and sequencing were performed by Novogene Bioinformatics Technology Co., Ltd. (Beijing, China). Sequencing libraries were generated using an NEBNext ${ }^{\circledR}$ UltraTM RNA Library Prep Kit for Illumina ${ }^{\circledR}$ (NEB, USA) following the manufacturer's recommendations. Index codes were added to attribute sequences to each sample. Briefly, total RNA was isolated using TRIzol reagent (Invitrogen, NJ, USA), and genomic DNA was then removed using DNase I (Invitrogen). mRNA was purified from total RNA using poly-T oligo-attached magnetic beads. First strand cDNA was synthesized using random hexamer primers. Second strand cDNA synthesis was subsequently performed using DNA polymerase I and RNase $\mathrm{H}$. The double-stranded cDNAs were purified using AMPure XP beads, then used for end reparation and "A" base addition, and finally ligated with sequencing adapters. The adaptor-ligated fragments were size selected using AMPure XP beads. After quantification using a Qubit 2.0 fluorometer (Life Technologies), cDNAs were used for PCR amplification and sequenced as $2 \times 120$ bp paired-end reads on an Illumina HiSeq ${ }^{\mathrm{TM}} 2000$ sequencer (Illumina, San Diego,
CA, USA). FeatureCounts v1.5.0-p3 was used to count the read numbers mapped to each gene, and then the FPKM (number of Fragments Per Kilobase of transcript sequence per Millions base pairs sequenced) of each gene was calculated based on the length of the gene. Differential expression analysis of two conditions/groups (two biological replicates per condition) was performed using the DESeq2 $\mathrm{R}$ package. The resulting $P$-values were adjusted using Benjamini and Hochberg's approach for controlling the false discovery rate. Genes with an adjusted $P$ value $<0.05$ found by DESeq 2 were assigned as differentially expressed. Finally, GO and KEGG analyses were performed to understand the effect of $\mathrm{Xn}$ on cell biological processes, molecular function, and cellular components. All raw sequence reads data were deposited in the NCBI Sequence Read Archive (SRA) with accession number PRJNA516508.

\section{Plasmid construction}

Total RNA was extracted from PAMs using a Total RNA Kit I (Omega Bio-tek, Norcross, GA, USA), and cDNA synthesis was performed with SuperScript III Reverse Transcriptase (Invitrogen). HMOX1 was generated by PCR amplification of CDNA from PAMs with the oligonucleotide pair SacI HMOX1 5'-ACG AGC TCA TGG AGC GTC TGC AAC CCG ACA- $3^{\prime}$ and NheI HMOX1 5'-CGG CTA GCT CAA GCA ACG TCC GGA ACG TCG TAC GGG TAC ATG GCA TAA AGC-3'. The sequence of the amplification product was compared to that in the NCBI database for verification (GenBank accession no. NM_001004027.1), restriction digested, and cloned into the pCAGGS vector with an HA tag at its $3^{\prime}$ end to produce pCAGGS-HMOX1.

\section{Plasmid transfection and virus challenge}

To determine the effects of HMOX1 on PRRSV replication, Marc-145 cells plated in 24-well plates were transfected with $0,0.4,0.6$ or $1.0 \mu \mathrm{g}$ of pCAGGS-HMOX1 using Lipofectamine 3000 (Invitrogen) according to the manufacturer's recommendations. Twenty-four hours after transfection, the cells were infected with PRRSV (0.01 MOI) and then harvested for Western blotting at 48 hpi.

\section{Small interfering RNA assays}

A total of $2 \times 10^{6}$ Marc-145 cells were transfected into 24-well plates with $50 \mathrm{pmol}$ of siNC (negative control) and siNrf2 (GenePharma, Shanghai, China) using $5 \mu \mathrm{L}$ of Lipofectamine RNAiMAX (Invitrogen, Carlsbad, CA, USA). After $24 \mathrm{~h}$, the cells were treated with $\mathrm{Xn}$ and infected with PRRSV (0.01 MOI) for $36 \mathrm{~h}$. Cells were harvested for Western blotting and qRT-PCR. The sequences of siRNAs targeting Nrf2 were: (a) 5'-AGA CAA ACA 
TTC AAG CCG-3'; (b) 5'-AGA ATA AAG TGG CTG CTC-3'.

\section{Reactive oxygen species (ROS) levels}

Cellular levels of reactive oxygen species were determined using a dichlorofluorescein (DCF) ROS assay kit according to the manufacturer's instructions (Beyotime Biotechnology, China). Marc-145 and PAM cells were infected with PRRSV (0.1 MOI) for $12 \mathrm{~h}$ and then treated with $5 \mu \mathrm{M}$ Xn or DMSO for another $12 \mathrm{~h} .10 \mathrm{mM}$ DCFDA was added to the cells for $30 \mathrm{~min}$ at $37^{\circ} \mathrm{C}$. The Marc145 cells were washed and imaged using an inverted fluorescence microscope (Nikon). The PAMs were collected by centrifugation, washed, and suspended in cold PBS; fluorescent intensity was analysed on a FACSCalibur (BD Biosciences, San Jose, CA, USA), and the data were analysed using FlowJo version 7.6.1. Cells treated with $12 \mu \mathrm{M} \mathrm{H}_{2} \mathrm{O}_{2}$ for $3 \mathrm{~h}$, washed, and then treated with DMSO or $5 \mu \mathrm{M}$ Xn for another $12 \mathrm{~h}$ served as positive controls.

\section{MDA, GSH and SOD levels}

Levels of superoxide dismutase (SOD), glutathione peroxidase (GSH), and malondialdehyde (MDA) in cells were determined using a Superoxide Dismutase (SOD) assay kit, a Glutathione Peroxidase (GSH-PX) assay kit, and a Microscale Malondialdehyde (MDA) assay kit, respectively, following the manufacturers' instructions (Jiancheng Bioengineering Institute, Nanjing, China). The levels were normalized to the protein concentration determined by a bicinchoninic acid (BCA) protein assay kit (Beyotime).

\section{Statistical analyses}

All statistical analyses were performed using GraphPad Prism (version 7.0, GraphPad Software, San Diego, CA, USA), and the data are expressed as the mean \pm standard error of the mean. The significance of differences among groups was determined by one-way or two-way analysis of variance (ANOVA). Differences with $p$-values $<0.05$ were considered significant and are designated with * in the figures.

\section{Results}

\section{Library screening}

Marc-145 cells were treated with $10 \mu \mathrm{M}$ natural product and infected with PRRSV as detailed in the timeline (Figure 1A). The results revealed that 24 (6.21\%) compounds showed no apparent cytotoxicity and reduced CPE by $50 \%$ compared to that with DMSO alone. These compounds were subjected to a second round of screening (Figure 1B). Five of these compounds produced minimal cytotoxicity and inhibited PRRSV infection (0.01 MOI and $0.1 \mathrm{MOI}$ ) by more than $80 \%$, as determined by IFA (Figures $1 \mathrm{C}$ and $\mathrm{D}$ ). Of these 5 compounds, only xanthohumol (Xn), curcumin, and chloroxin inhibited PRRSV in a dose-dependent manner and had a selectivity index (SI) greater than 10 (Figures $1 \mathrm{E}$ and $\mathrm{F}$ ).

To determine the dose range of Xn anti-PRRSV activity, Marc-145 cells were treated with 5, 10, and $15 \mu \mathrm{M}$ $\mathrm{Xn}$ for $1 \mathrm{~h}$ and then infected with PRRSV (0.01 MOI). $\mathrm{TCID}_{50}$ and qRT-PCR assays performed at 24, 36, and 48 hpi showed that virus titres and ORF7 mRNA levels decreased in a dose-dependent manner at each postinfection time point (Figures $2 \mathrm{~A}$ and $\mathrm{B}$ ). At $48 \mathrm{hpi}, \mathrm{CPE}$ and IFA revealed that the number of infected cells in the Xn-treated groups was obviously less than that in the negative control (Figure 2C). Western blot analysis demonstrated that Xn was as effective at reducing replication of the C-PRRSV S1 strain as it was at reducing replication of the BB0907 strain and was somewhat effective at reducing replication of the NADC30-like FJ1402 strain (Figure 2D).

\section{Xanthohumol inhibits PRRSV infection}

To begin to determine the mechanism of Xn inhibition of PRRSV, Marc-145 cells were treated with Xn before, during, and after PRRSV infection (Figure 3A). At $48 \mathrm{hpi}$, cells were observed for CPE, stained for IFA, and harvested for Western blotting. PRRSV inhibition was greatest in cells treated with $\mathrm{Xn}$ for $1 \mathrm{~h}$ before infection and was significantly suppressed in cells treated with Xn during infection. In cells treated with Xn for $24 \mathrm{~h}$ after infection, PRRSV was still suppressed but not to the extent seen in the pre- and co-treated cells (Figures $3 \mathrm{~B}$ and $\mathrm{C}$ ). To determine if Xn affected PRRSV directly, $10 \mu \mathrm{M} \mathrm{Xn}$ was mixed with virus, incubated for $2 \mathrm{~h}$ at $37^{\circ} \mathrm{C}$ and then added onto Marc- 145 cells. As shown in Figure 3D, the number of viral plaques in Xn+PRRSV cells was not obviously different from that in the DMSO+PRRSV control cells, indicating that Xn does not have a direct virucidal effect on PRRSV. Together, these data indicated that Xn inhibits PRRSV early in the infection process.

To determine what stage of the PRRSV life cycle is specifically affected by Xn, Marc-145 cells were chilled at $4{ }^{\circ} \mathrm{C}$ for $1 \mathrm{~h}$, and the culture supernatants were then replaced with a $4{ }^{\circ} \mathrm{C}$ mixture of $\mathrm{Xn}$ or DMSO and PRRSV (1 MOI). After incubation at $4{ }^{\circ} \mathrm{C}$ for another $1 \mathrm{~h}$, the cells were washed and harvested for qRT-PCR of PRRSV ORF7 mRNA. The results showed that treatment with $\mathrm{Xn}$ resulted in reduced viral RNA detection in a dose-dependent manner, indicating that $\mathrm{Xn}$ affects PRRSV at the adsorption stage (Figure 4A). In a companion experiment, cells (pre-treated with $10 \mu \mathrm{g} /$ mL CHX for $12 \mathrm{~h}$ ) were incubated with PRRSV for $1 \mathrm{~h}$ at $4{ }^{\circ} \mathrm{C}$ (to allow virus to attach), washed, and then 

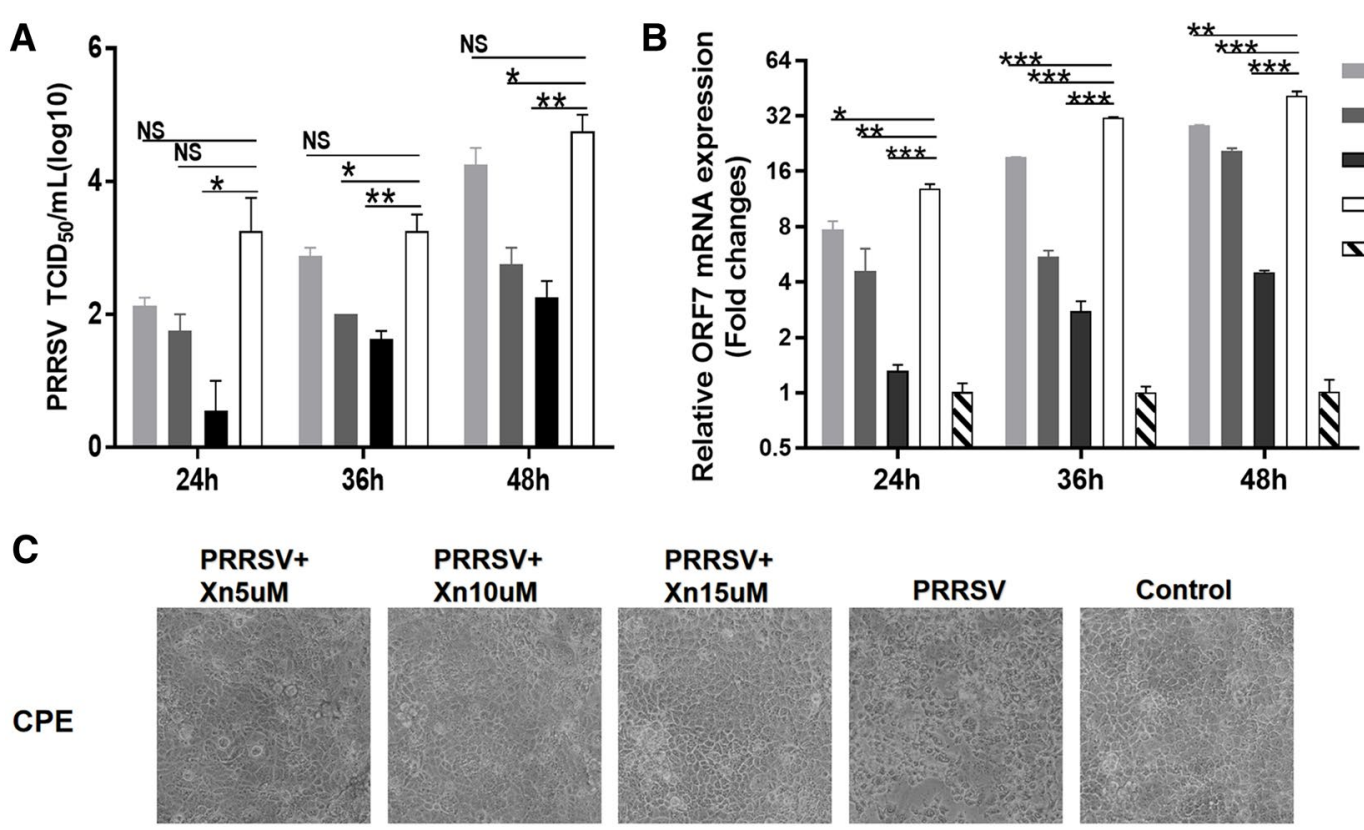

\section{PRRSV+ Xn15uM}
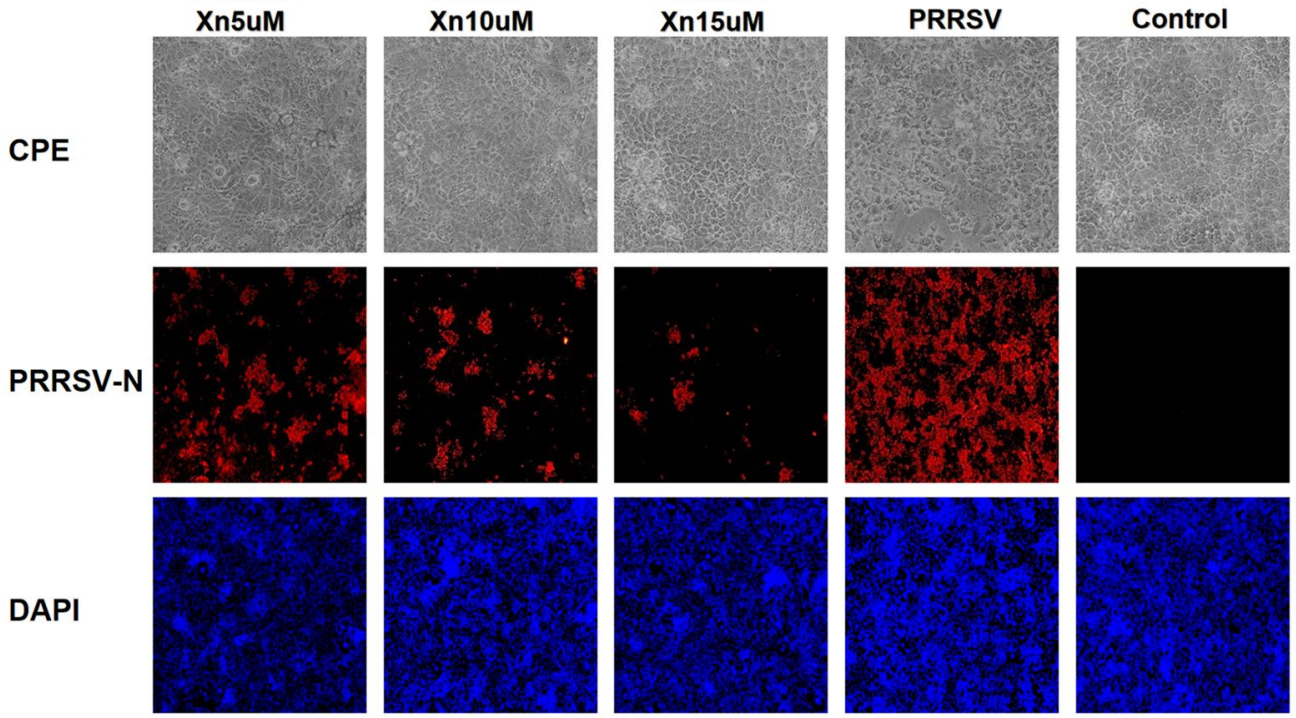

D

s1

BB0907

FJ1402

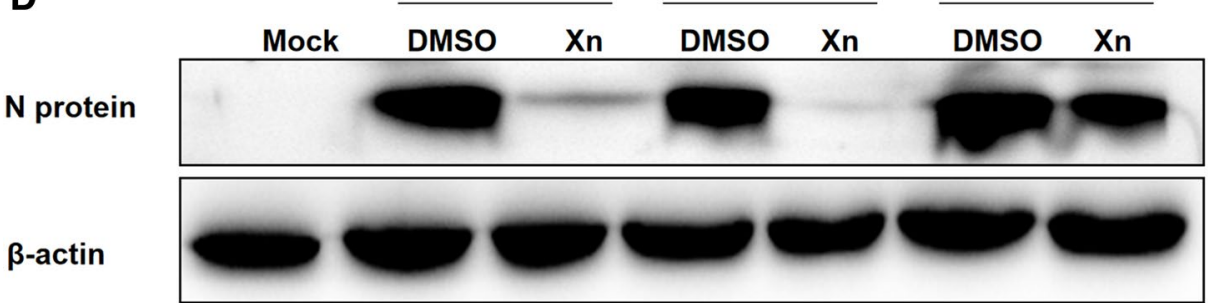

Figure 2 Identification of anti-PRRSV activity of Xn in Marc-145 cells. Marc-145 cells were pre-treated with the indicated concentrations of $\mathrm{Xn}(\mathbf{A}-\mathbf{C})$ or $10 \mu \mathrm{M} \mathrm{Xn}(\mathbf{D})$ for $1 \mathrm{~h}$ and then infected with PRRSV $(0.01 \mathrm{MOl})$ for $1 \mathrm{~h}$ at $37^{\circ} \mathrm{C}$. Cells were washed with PBS and then incubated in fresh medium containing $\mathrm{Xn}$ for $48 \mathrm{~h}(\mathbf{C})$ or the indicated times $(\mathbf{A}, \mathbf{B})$. DMSO served as the treatment control. A Culture supernatants were collected at the indicated time points for viral titration. The results are expressed as a $50 \%$ tissue culture infective dose $\left(\mathrm{TCID}_{50}\right)$. Titres from three independent experiments are shown as the means \pm SEMs (error bars). B Relative PRRSV ORF7 mRNA levels determined by qRT-PCR and expressed relative to ORF7 mRNA levels in mock cells. GAPDH was the internal loading control. C At 48 hpi, light microscopy and IFA images of Marc-145 PRRSV-infected and Xn-treated cells. Viral N-protein is red, and nuclei are blue. D At $48 \mathrm{hpi}$, Western blot of N-protein in cells infected with different PRRSV genotypes and treated with $10 \mu \mathrm{M} X \mathrm{n}$ or DMSO. All assays were performed in triplicate, with three technical repeats for each sample. Bars represent means \pm SEMs from three independent experiments. ${ }^{* *} P<0.001 ;{ }^{*} P<0.01 ;{ }^{*} P<0.05$ 
A

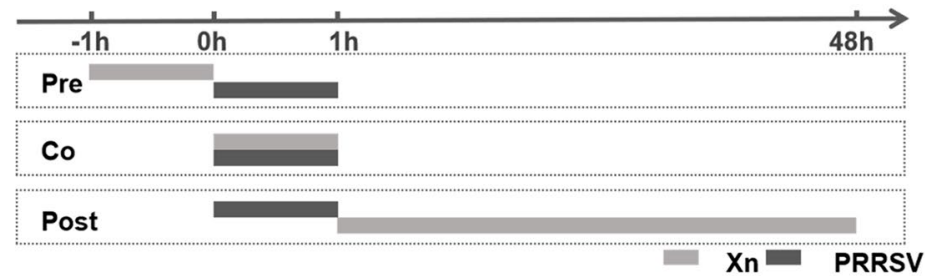

B
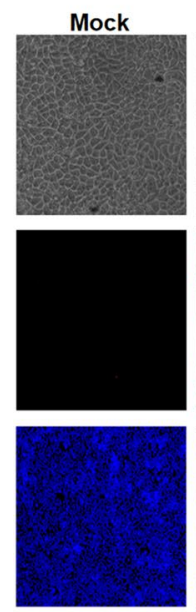
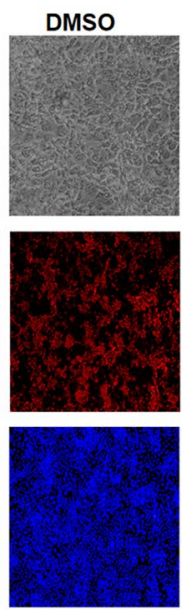
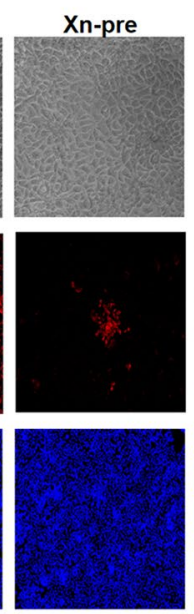
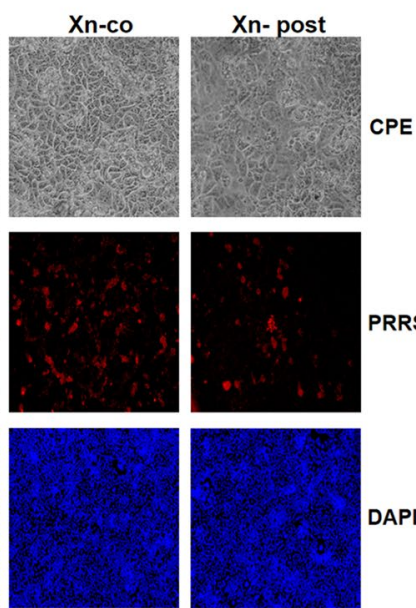
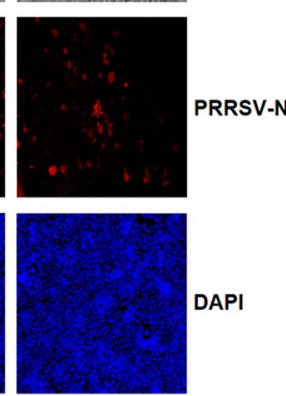

C Pre
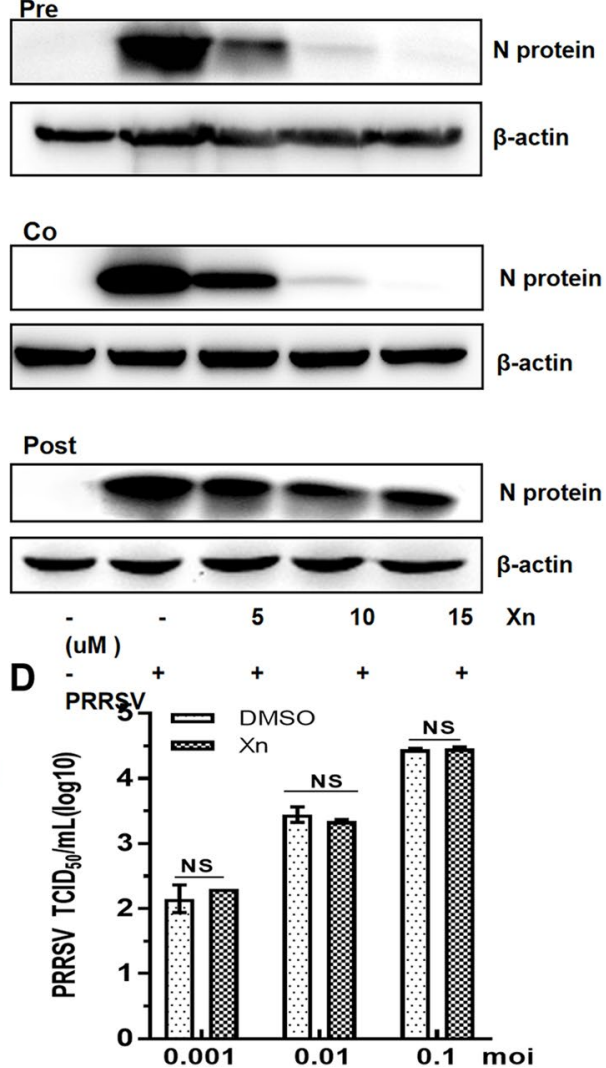

Figure 3 Xanthohumol inhibits PRRSV early in infection in Marc-145 cells. A Time-of-addition schematic. Marc-145 cells were infected with PRRSV (0.01 MOI) for $1 \mathrm{~h}(0$ to $1 \mathrm{~h})$, and cells were treated with $10 \mu \mathrm{M} X \mathrm{n}$ at different times of infection, designated pre-treatment (pre), co-treatment (co), or post-treatment (post). B The effect of Xn was determined by CPE and IFA. C The effect of different concentrations of Xn was detected by Western blotting. $\mathbf{D}$ Xn $(10 \mu \mathrm{M})$ or DMSO was incubated with PRRSV $(0.001,0.01$, and $0.1 \mathrm{MOI})$ for $2 \mathrm{~h}$ at $37^{\circ} \mathrm{C}$ and then inoculated into Marc-145 cells. After incubation for $48 \mathrm{~h}$ at $37^{\circ} \mathrm{C}$, the viral titres were detected by $\mathrm{TCID}_{50}$ assays. The results are representative of three independent experiments performed in triplicate

incubated in fresh DMEM-2\% FBS containing $10 \mu \mathrm{M}$ $\mathrm{Xn}$ for $2 \mathrm{~h}$ at $37{ }^{\circ} \mathrm{C}$. The cells were probed for PRRSV $\mathrm{N}$-protein and observed by confocal laser-scanning microscopy. The results showed that Xn inhibits PRRSV entry into cells even after the virus has attached to the cells (Figure 4B). In cells incubated with PRRSV for $6 \mathrm{~h}$ at $37{ }^{\circ} \mathrm{C}$ and then treated with $\mathrm{Xn}$ in fresh DMEM- $2 \%$ FBS at $37^{\circ} \mathrm{C}$ for an additional $1,2,3$, and $4 \mathrm{~h}$, qRT-PCR results showed that viral mRNA levels in the $\mathrm{Xn}$-treated cells were not significantly different from those in the DMSO-treated control cells (Figure 4C). To explore the role of Xn in PRRSV release, Marc-145 cells were incubated with PRRSV for $24 \mathrm{~h}$. The cells were washed and then incubated with fresh DMEM containing Xn for 10,30 , and $60 \mathrm{~min}$. The virus titres in the supernatants from the Xn-treated cells were not significantly different than those in the supernatants from the DMSOtreated control cells (Figure 4D). Taken together, these results indicate that $\mathrm{Xn}$ inhibits PRRSV at the stages of adsorption and internalization.

\section{Transcriptional response of Marc-145 cells to xanthohumol treatment}

The effect of xanthohumol on the activation of the Nrf2 pathway in human hepatocellular carcinoma (HCC) HepG2 cells, immortalized human liver THLE-2 cells and mouse lung tissues $[21,22]$ has been reported. To investigate the mechanism underlying the anti-PRRSV effect of $\mathrm{Xn}$, we used high-throughput RNA sequencing to examine gene expression in Marc-145 cells that had been treated with $10 \mu \mathrm{M}$ Xn or DMSO for 4,8 , and $12 \mathrm{~h}$. Figure 6A shows the numbers of differentially expressed genes (DEGs) that were identified at each time point, using the criteria of $p<0.05$. We classified a gene as upregulated if its transcript was more abundant in cells treated with $\mathrm{Xn}$ than in cells treated with DMSO. 
A
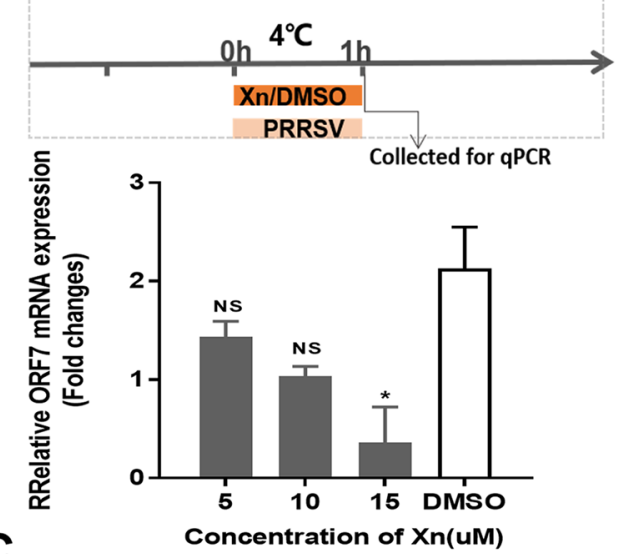

C
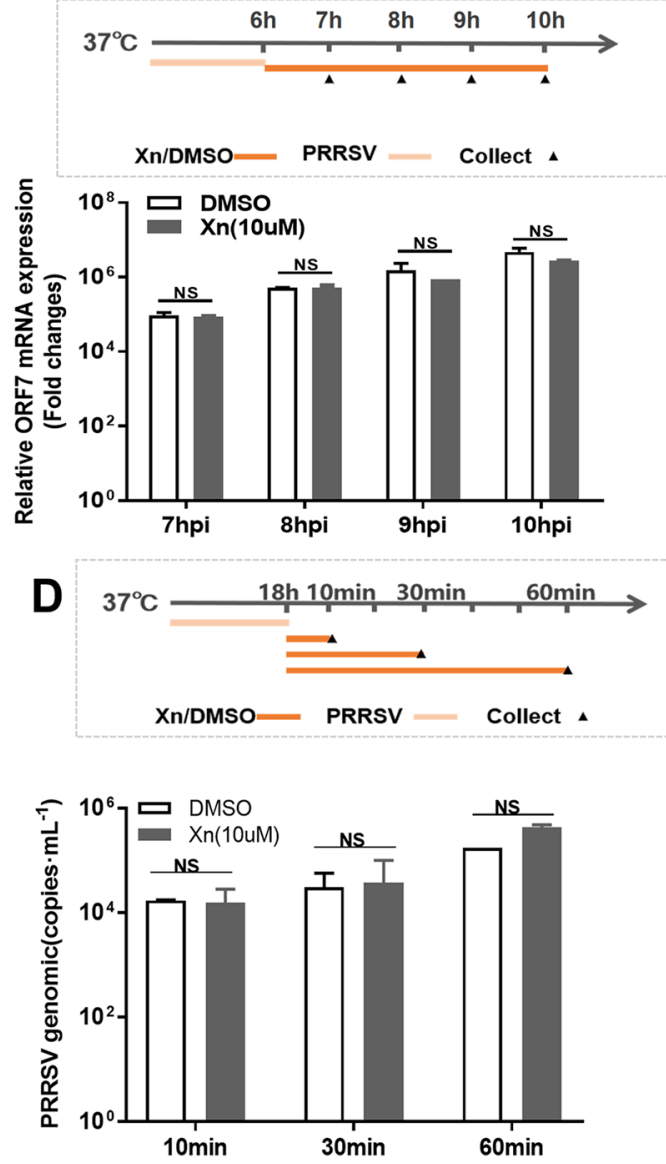

B
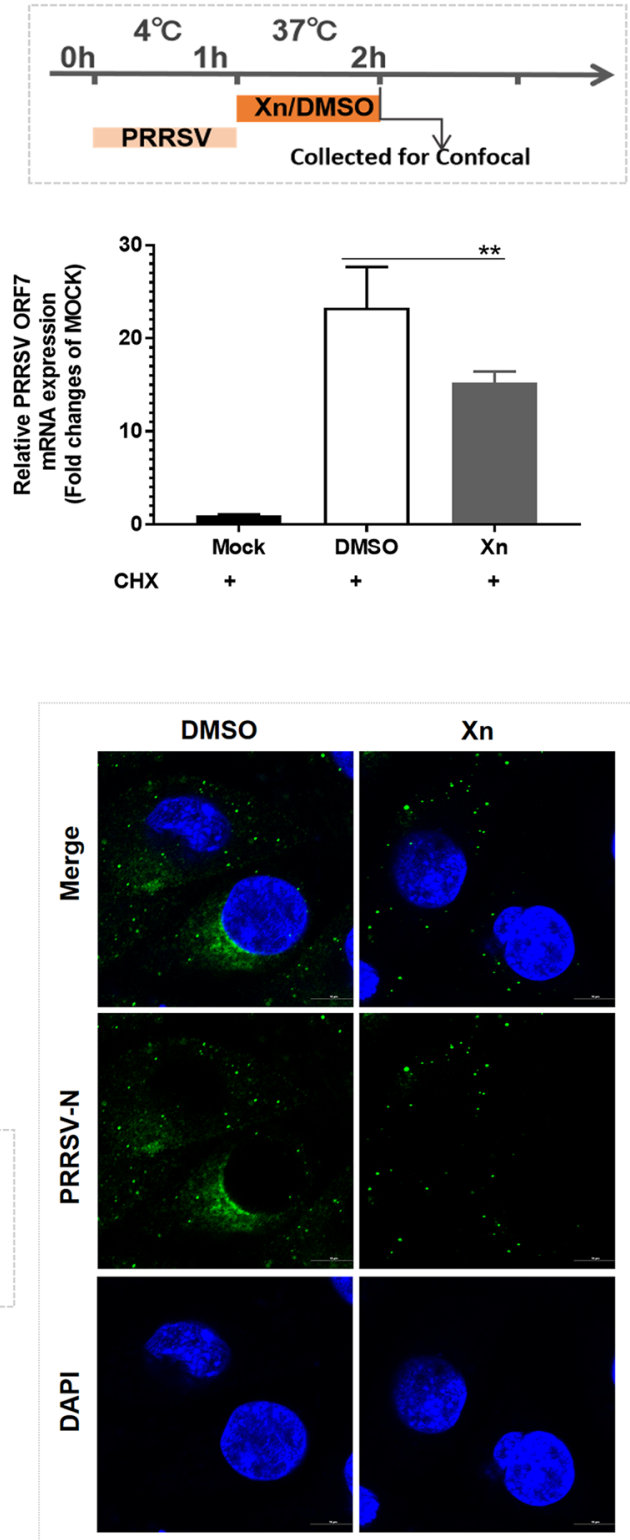

Figure $4 \mathrm{Xn}$ inhibits PRRSV adsorption and internalization in Marc-145 cells. A Adsorption assay. Cells were incubated with a mixture of Xn or DMSO and PRRSV for $1 \mathrm{~h}$ at $4{ }^{\circ} \mathrm{C}$ and then harvested for qRT-PCR. B Internalization assay. Cells were treated with CHX (10 $\left.\mu \mathrm{g} / \mathrm{mL}\right)$ for $12 \mathrm{~h}$ first, then incubated with PRRSV (1 MOI) for $1 \mathrm{~h}$ at $4{ }^{\circ} \mathrm{C}$, washed, and finally incubated with $10 \mu \mathrm{M}$ Xn or DMSO for another $1 \mathrm{~h}$ at $37^{\circ} \mathrm{C}$. The levels of PRRSV ORF7 mRNA were detected by qRT-PCR, and the visible virions in cells were detected using IFA confocal laser-scanning microscopy. Scale bar $10 \mu \mathrm{m}$. C Cells were infected with PRRSV (1 MOI) for $6 \mathrm{~h}$, and culture medium was replaced with 2\% DMEM containing Xn (10 $\mu \mathrm{M})$ or DMSO. At 7, 8, 9, and $10 \mathrm{hpi}$, the PRRSV ORF7 levels were measured using qRT-PCR. D Cells were infected with PRRSV (0.1 MOI) for $18 \mathrm{~h}$, then washed and incubated with fresh DMEM containing $10 \mu \mathrm{M}$ Xn or DMSO. Supernatants were harvested, and released virus was titred by plaque assay. qRT-PCR results are presented relative to the reference control (mock infected cells). GAPDH was used as the internal loading control. All assays were repeated at least three times, with each experiment performed in triplicate. Bars represent the means \pm SEMs from three independent experiments. ${ }^{* *} P<0.01$; * $P<0.05$ compared with the DMSO-treated group 
The number of DEGs increased with treatment time, and after 12 h, 2493 genes were upregulated, and 3065 downregulated. In total, 462 DEGs appeared at all three sampled times (Figures $5 \mathrm{~B}$ and $\mathrm{C}$ ). GO analysis of the DEGs showed that the most enriched molecular functions were oxidoreductase activity and oxidation-reduction processes, as marked by asterisks (Figure 5D). GO analysis of the top 100 DEGs according to $\log 2$ fold change at $8 \mathrm{~h}$ suggested that oxidoreductase activity and the oxidoreductase complex were activated at this time point (Additional file 1). We therefore investigated the networks associated with oxidoreductase and the antioxidant response. Further analysis identified a large set of genes associated with the antioxidant response, including Nrf2, HMOX1, GCLC, GCLM, and NQO1 (Figure 6A). These genes, which are all part of the Nrf2 signalling pathway, are transcriptionally activated through mainly binding of $\mathrm{Nrf} 2$ to antioxidant response elements (AREs) at their $5^{\prime}$ promoters [23].

To confirm the results of the RNA-seq analysis, a qRTPCR assay was conducted to measure the expression of Nrf2, HMOX1, GCLC, GCLM, NQO1, TXNIP, and TXNRD1 in Xn-treated cells. The results (Figures 6B$\mathrm{H}$ ) showed that $\mathrm{Xn}$ treatment increased the expression of all 7 genes, consistent with the RNA-seq data. Taken together, these data indicate that $\mathrm{Xn}$ may protect against PRRSV infection by activating the host antioxidant response via stimulation of the Nrf2 signalling pathway.

\section{Xanthohumol upregulates the Nrf2 antioxidative pathway, inhibiting PRRSV proliferation}

HMOX1 (haem oxygenase 1) was highly upregulated at all three points in the RNA-seq analysis; it is a ratelimiting enzyme in haem degradation, has cytoprotective effects against oxidative stress, and plays an important role in the resolution of inflammation [24]. To examine the role of Xn-induced HMOX1 expression in PRRSV suppression, Marc-145 cells were treated with $10 \mu \mathrm{M}$ Xn for different times over $24 \mathrm{~h}$, followed by qRT-PCR for HMOX1 mRNA. As shown in Figure 7A, HMOX1 was induced by $\mathrm{Xn}$ in cells as a function of time until late in the experiment when induction levels fell sharply, indicating that $\mathrm{Xn}$ provides a continuous stimulus on HMOX1. We therefore investigated the role that HMOX1 plays in the protective effect of Xn against PRRSV in Marc-145 and PAM cells. Marc- 145 cells, when $70 \%$ confluent, were transfected with different doses of pCAGGSHMOX1 and pCAGGS and then infected with PRRSV (MOI 0.01). At $48 \mathrm{hpi}$, the levels of viral N-protein and HMOX1 in the cell lysates were examined by Western blotting. The levels of viral ORF7 mRNA and titres were detected by qRT-PCR and TCID $_{50}$ assays. As expected, overexpression of HMOX1 in Marc-145 cells significantly inhibited PRRSV replication in a dose-dependent manner (Figures $7 \mathrm{~B}$ and $\mathrm{D}$ ). These results indicated that $\mathrm{Xn}$ inhibition of PRRSV is related to HMOX1.

$H M O X 1$ transcription is modulated by an intertwined circuit in which nuclear factor E2-related factor 2 (Nrf2) plays an essential role [25]. To examine the role of Nrf2 in the action of Xn against PRRSV infection, Marc-145 cells were infected with PRRSV (0.1 MOI) for $1 \mathrm{~h}$ at $37^{\circ} \mathrm{C}$ and then cultured in medium containing $10 \mu \mathrm{M}$ $\mathrm{Xn}$ or DMSO for $24 \mathrm{~h}$. Total RNA was extracted from virus-infected cell lysates, and PRRSV ORF7 mRNA levels and the levels of a set of Nrf2-regulated antioxidant genes were quantified by qRT-PCR. As shown in Figure 7E, the expression of these Nrf2-regulated genes was downregulated slightly by PRRSV infection but significantly induced by $\mathrm{Xn}$ treatment. Infected cells treated with Xn had elevated mRNA expression of Nrf2 and its target genes, as well as decreased virus replication. Because we did not have a suitable Nrf2 antibody for detecting endogenous Nrf2 protein in Marc-145 cells, we used HMOX1 as an indicator of Nrf2 levels. As shown in Figure 7F, along with the decrease in N-protein, in PRRSV-infected cells treated with $\mathrm{Xn}$, there was an accompanying increase in HMOX1. Xn treatment significantly inhibited PRRSV replication. In addition, Marc145 cells were transfected with siRNAs against Nrf2 or with a nonspecific siRNA control (NC). After incubation for $24 \mathrm{~h}$, cells were infected with PRRSV (0.01 MOI). At $36 \mathrm{hpi}$, cells were harvested for qRT-PCR and Western blotting. The results showed that the siRNAs siNrf2a and siNrf2-b efficiently knocked down Nrf2 mRNA and protein levels (Figures $7 \mathrm{G}$ and $\mathrm{H}$ ) and resulted in a significant increase in PRRSV replication. These results indicate that Nrf2 is a crucial protein involved in the host defence mechanism against PRRSV.

Finally, to identify the role of Nrf2 in the anti-PRRSV effect of Xn, Marc-145 cells were transfected with siNrf2a or siNC. After $24 \mathrm{~h}$, the cells were treated with $10 \mu \mathrm{M}$ $\mathrm{Xn}$ for $1 \mathrm{~h}$ and then infected with PRRSV (0.01 MOI). At $36 \mathrm{hpi}$, cells were harvested for qRT-PCR and Western blotting. As expected, Xn significantly decreased PRRSV ORF7 mRNA and N-protein levels in cells transfected with siNC. However, in cells transfected with siNrf2, Xn had no inhibitory effect on PRRSV infection (Figures 7I and J). These results suggest that Nrf2 could be an effective target against PRRSV and that the anti-PRRSV action of Xn depends on its activation of Nrf2 and the Nrf2-regulated antioxidant pathway.

\section{Xn alleviates PRRSV-stimulated oxidative stress}

In Marc-145 cells, PRRSV infection induces oxidative stress in cells by generating reactive oxygen species (ROS), which play a key role in PRRSV pathogenesis 


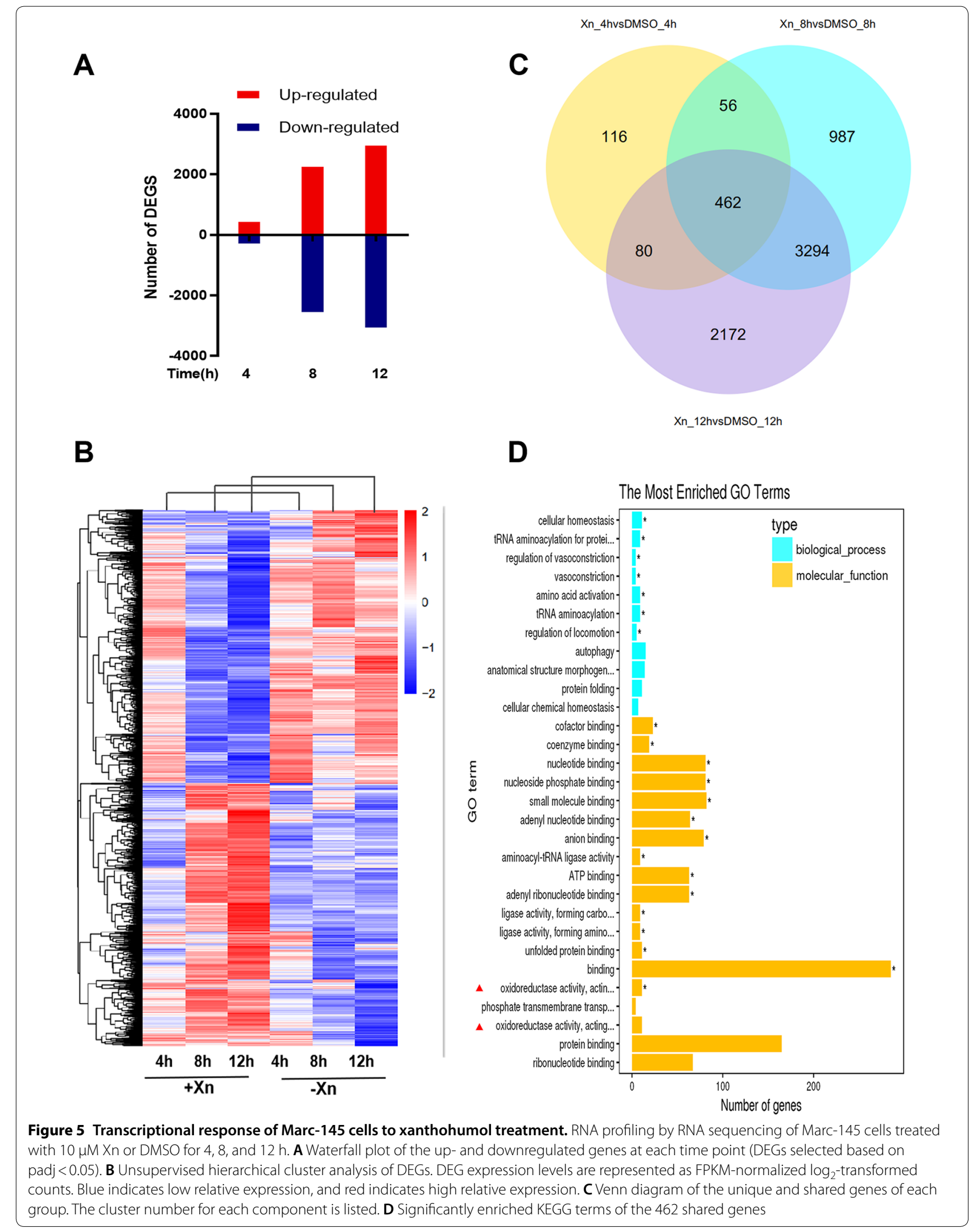




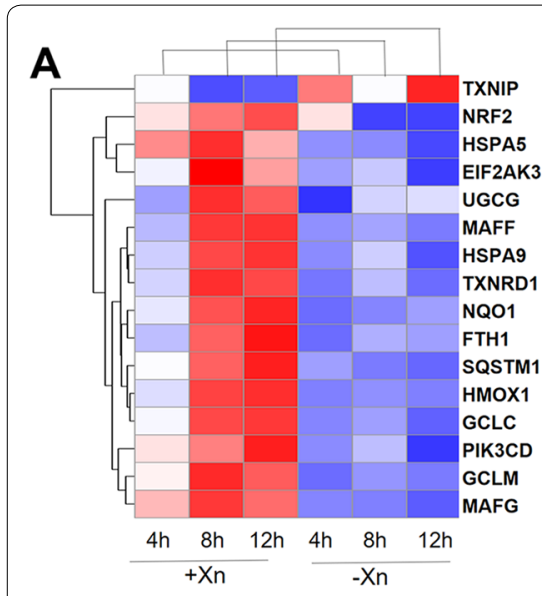

E

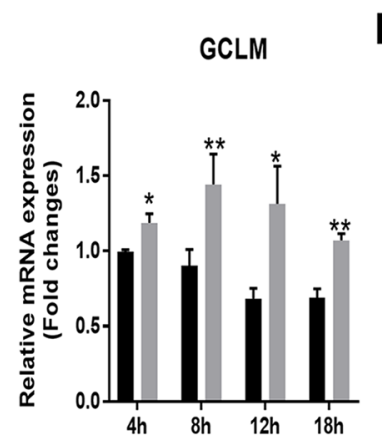

B

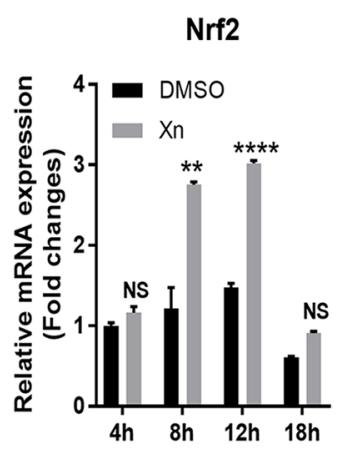

NQ01

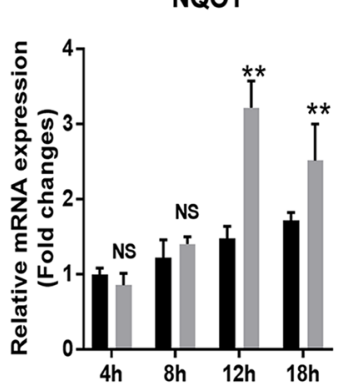

G
C

HMOX1

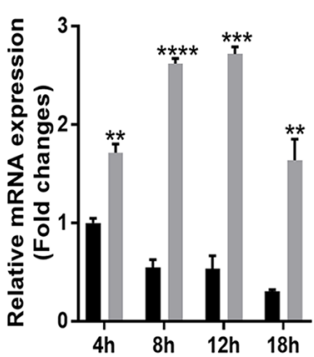

GCLC

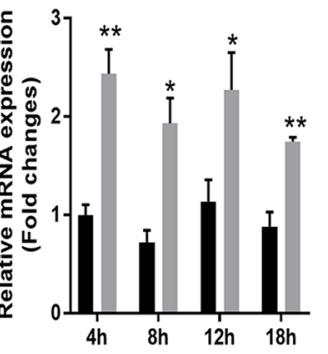

Txnip

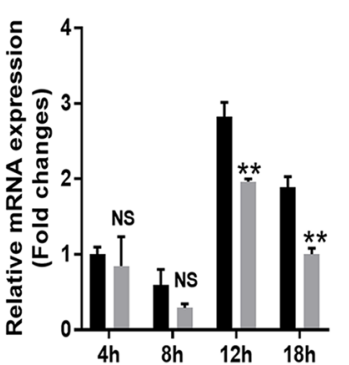

H

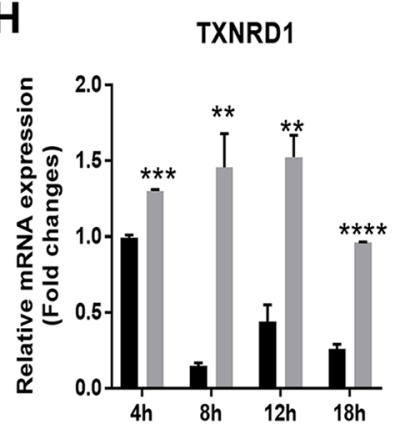

Figure 6 Xanthohumol treatment upregulates the Nrf2 antioxidative pathway. A Heat map of expressed Nrf2 antioxidant genes modulated by $10 \mu \mathrm{M}$ Xn or DMSO treatment in Marc-145 cells. Red and blue correspond to relative up- and downregulation, respectively. B-H qRT-PCR quantification of the expression levels of Nrf2-regulated genes at four time points after $10 \mu \mathrm{M}$ Xn treatment. The qRT-PCR was repeated at least three times, with each experiment performed in triplicate. ${ }^{* * *} P<0.0001$; ${ }^{* *} P<0.001$; ${ }^{* *} P<0.01 ;{ }^{*} P<0.05$ vs DMSO-treated cells for each time point

[26]. Because of our transcriptome data regarding Xninduced oxidoreductase activity and the Nrf2-regulated antioxidant genes and because Nrf2 plays a crucial role in oxidative stress [27], we explored further whether the inhibitory activity of Xn against PRRSV infection is related to its antioxidant activity. Marc-145 cells pretreated with $12 \mu \mathrm{M} \mathrm{H}_{2} \mathrm{O}_{2}$ for $3 \mathrm{~h}$ and then incubated with $\mathrm{Xn}$ produced less ROS than untreated cells. IFA results showed that PRRSV infection resulted in increased
ROS, and $\mathrm{Xn}$ treatment reduced ROS in infected and uninfected cells (Figure 8A). MDA, a product of lipid peroxidation and a biomarker for estimating oxidative stress, was also dramatically reduced by Xn treatment (Figure 8B). Furthermore, the reduction in SOD and glutathione peroxidase (GSH) as a result of PRRSV infection was alleviated by $\mathrm{Xn}$ (Figures $8 \mathrm{C}$ and $\mathrm{D}$ ). These data indicate that $\mathrm{Xn}$ restores the oxidation balance in Marc145 cells.

\footnotetext{
(See figure on next page.)

Figure 7 Xanthohumol upregulates Nrf2-HMOX1 to inhibit PRRSV proliferation. A Marc-145 cells were treated with $10 \mu \mathrm{M}$ Xn for different times over $24 \mathrm{~h}$, followed by qRT-PCR for HMOX1 mRNA. ${ }^{* * *} P<0.001$; ${ }^{* *} P<0.01$; ${ }^{*} P<0.05$ vs DMSO-treated cells. B-D PRRSV replication in Marc-145 cells transfected with the indicated doses of PCAGGS-HMOX 1 for $24 \mathrm{~h}$ and then infected with PRRSV $(0.01 \mathrm{MOI})$ for $48 \mathrm{~h}$ was evaluated by Western blotting, TCID 50 and qPCR. E Marc-145 cells were treated with Xn or DMSO for $1 \mathrm{~h}$, then infected with PRRSV (0.1 MOI) for $1 \mathrm{~h}$ at $37^{\circ} \mathrm{C}$ and finally cultured in medium containing $10 \mu \mathrm{M}$ Xn or DMSO. Total RNA was extracted from lysates of cells at $24 \mathrm{hpi}$, and the mRNA levels of PRRSV ORF7 and a set of Nrf2-regulated antioxidant genes were detected by qRT-PCR. ${ }^{\# \#} P<0.001 ;{ }^{\# \#} P<0.01 ;{ }^{\#} P<0.05$ vs DMSO-treated cells. ${ }^{* * *} P<0.001 ;{ }^{* *} P<0.01$; ${ }^{*} P<0.05$ vs DMSO + PRRSV cells. $\mathbf{F}$ Cells were lysed and samples were prepared for Western blotting. G qRT-PCR and $\mathbf{H}$ Western blot analysis were performed on Marc-145 cells transfected with 50 pmol of siNC or Nrf2 siRNAs (siNrf2-a and siNrf2-b) using $5 \mu$ L of Lipofectamine RNAiMAX transfection reagent for $24 \mathrm{~h}$. Cells were then infected with PRRSV ( $0.01 \mathrm{MOI})$, and after $36 \mathrm{~h}$, cells were harvested for assays. I qRT-PCR and $\mathbf{J}$ Western blot analysis were performed on Marc-145 cells transfected with siNrf2-a and siNC. After $24 \mathrm{~h}$, cells were treated with $10 \mu \mathrm{M}$ Xn or DMSO for $1 \mathrm{~h}$ and then infected with PRRSV $(0.01 \mathrm{MOI})$. After $36 \mathrm{~h}$, cells were harvested for assays. All results are means \pm standard deviations from three independent experiments performed in triplicate. ${ }^{* *} P<0.001 ;{ }^{*} P<0.01 ;{ }^{*} P<0.05$ compared with the control group
} 


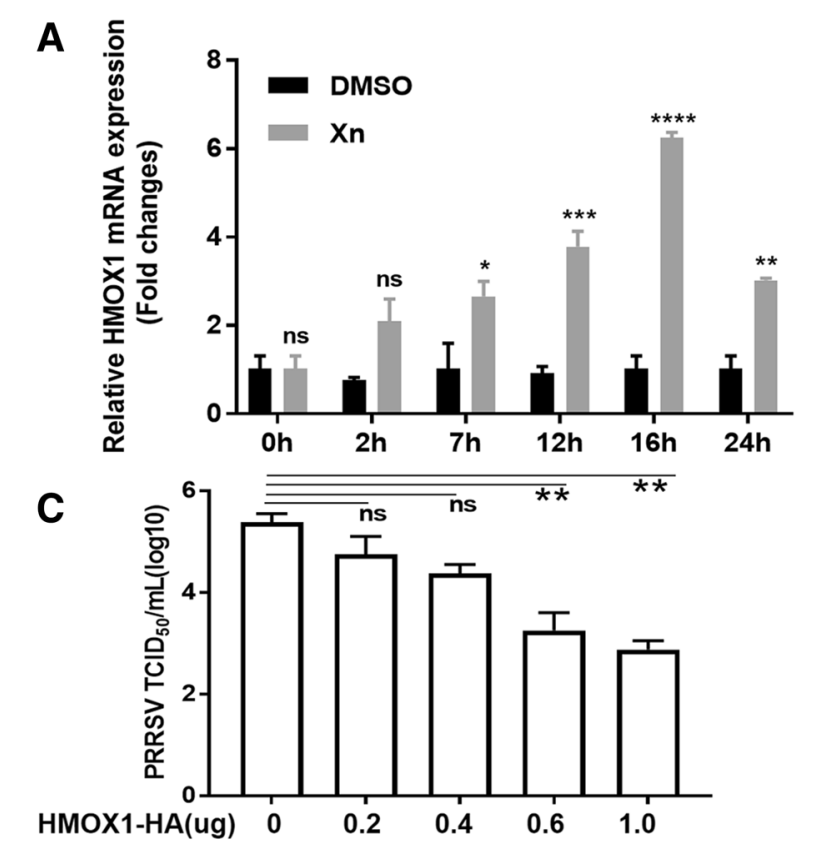

B
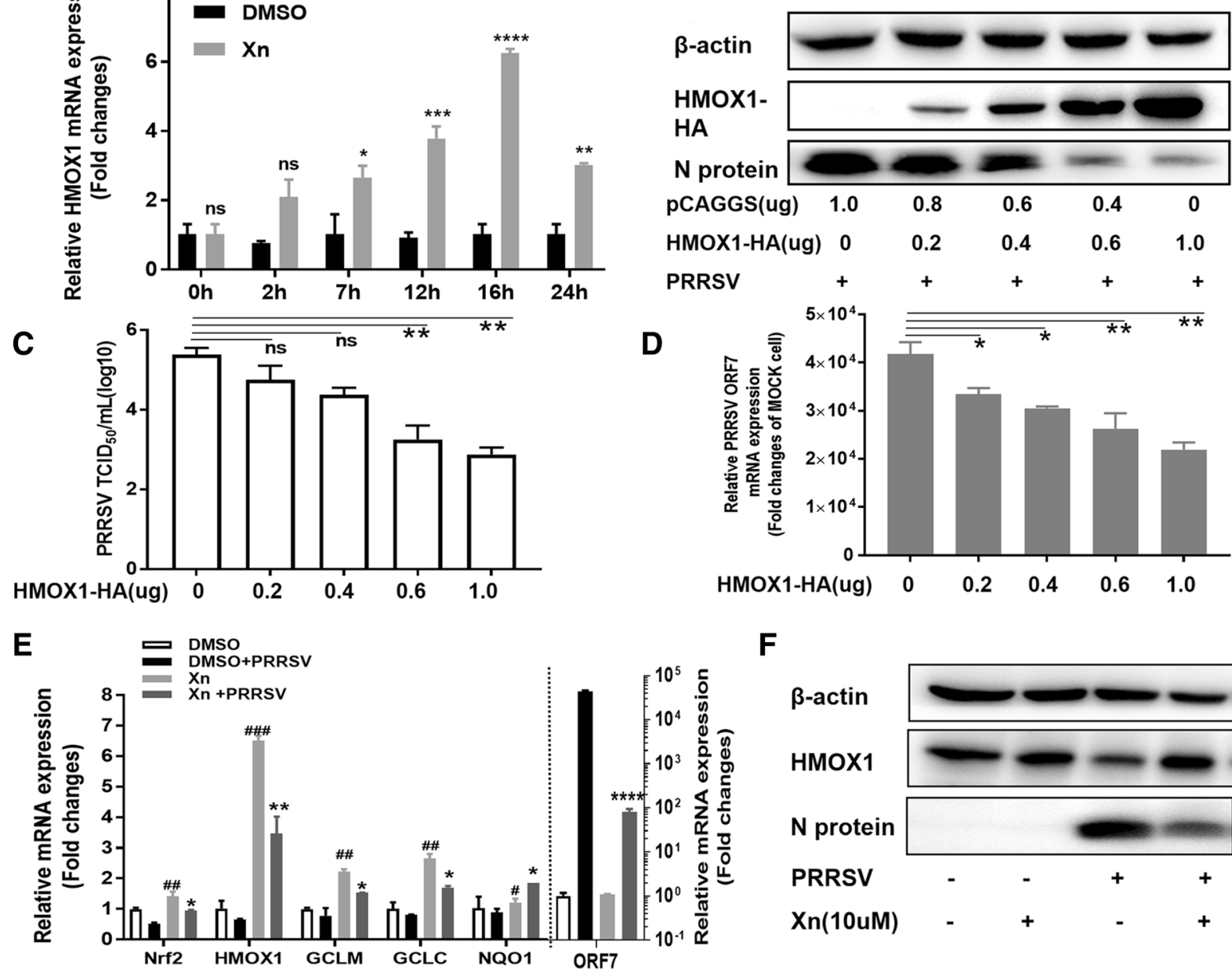

D

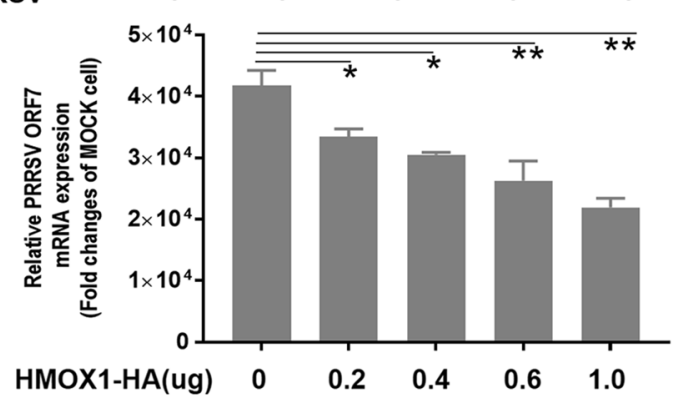

F

G

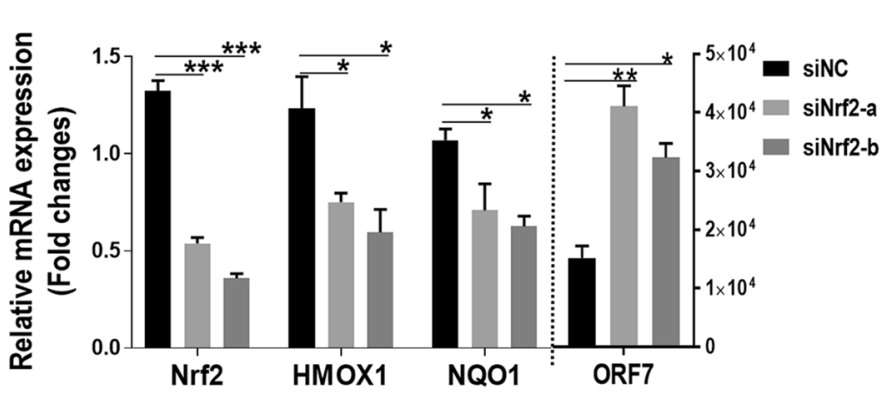

H

$\beta$-actin

HMOX1

$\mathrm{N}$ protein

PRRSV

$\mathrm{Xn}(10 \mathrm{uM})$
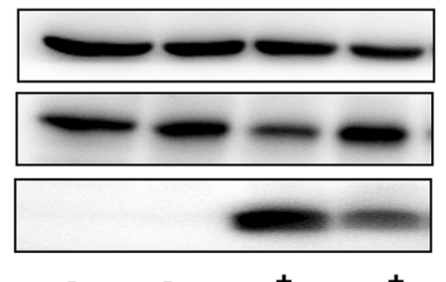

$\beta$-actin

Mock siNC siNrf2-a siNrf2-b

HMOX1

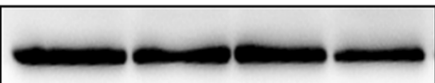

N protein

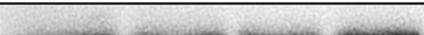

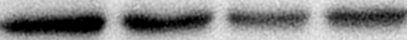

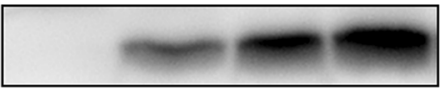

I

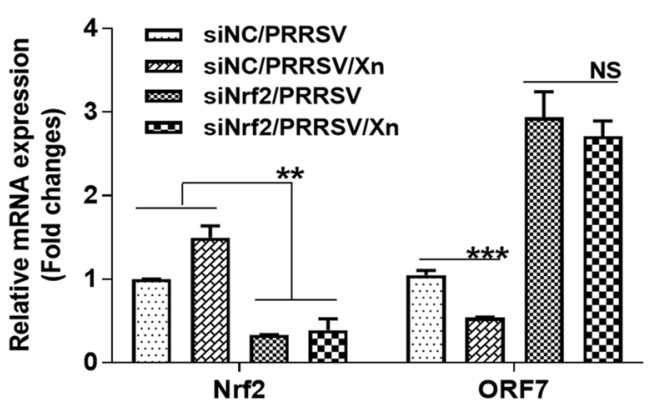

$\mathbf{J}_{\beta \text {-actin }}$

HMOX1

$\mathrm{N}$ protein

PRRSV + + + +

siNrf2-a $\quad-\quad+\quad+\quad+$

si NC

$\mathrm{Xn}(10 \mathrm{uM})$

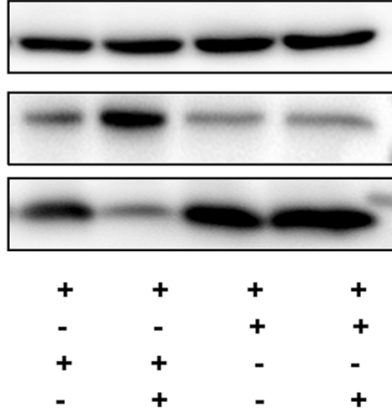


A
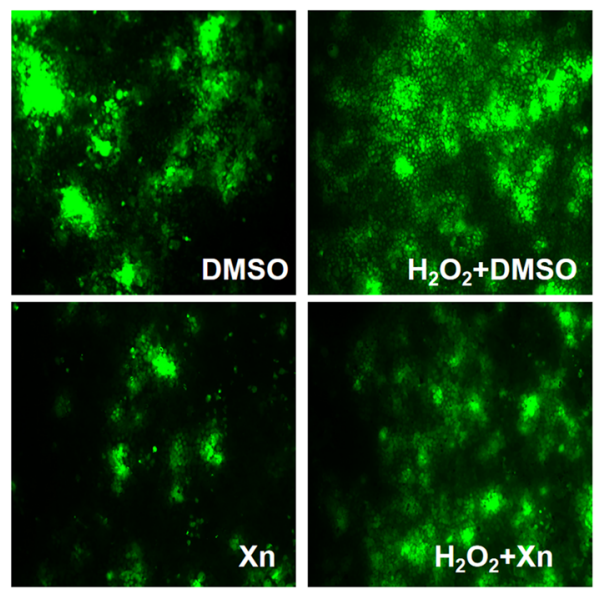
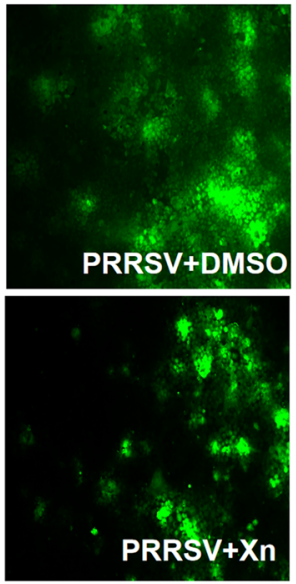

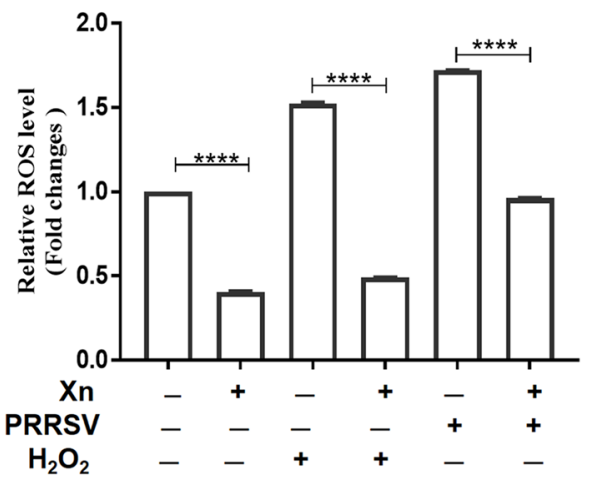

B
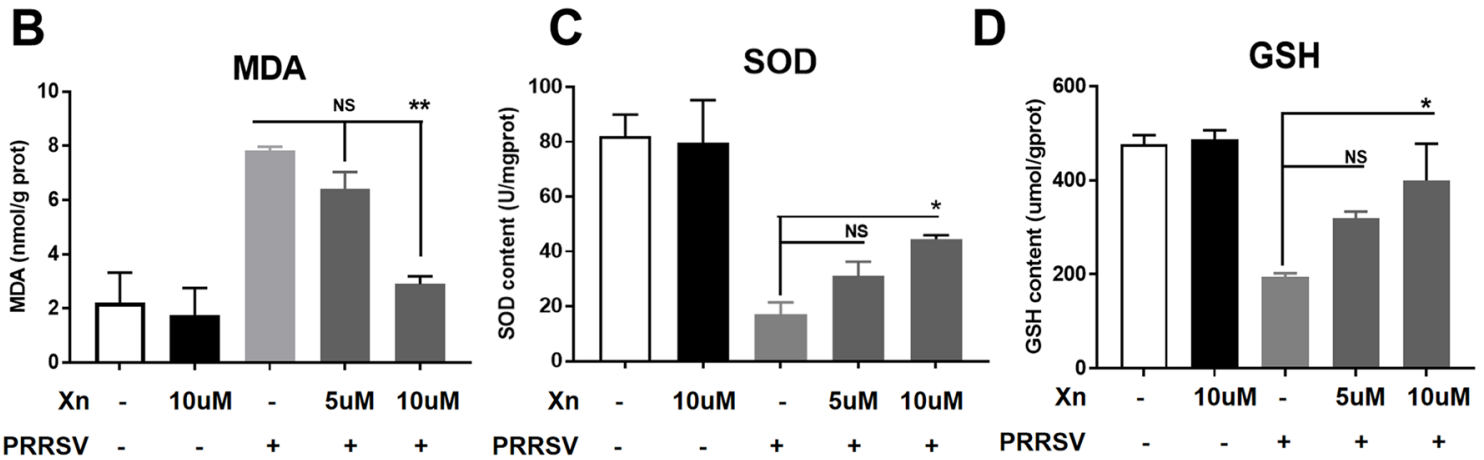

Figure 8 Xanthohumol suppresses oxidative stress induced by PRRSV in Marc-145 cells. A ROS generation in Marc-145 cells was determined using dichlorofluorescein (DCF), and images were acquired using an inverted fluorescence microscope (Nikon). ImageJ was used to quantify the intensity of the green fluorescence in the pictures. B-D Effects of Xn on MDA, SOD and GSH levels in PRRSV-infected Marc-145 cells. All results are means \pm standard deviations from three independent experiments performed in triplicate. ${ }^{* * *} P<0.001 ;{ }^{* *} P<0.01 ;{ }^{*} P<0.05$ compared with the PRRSV-infected cells

\section{Xanthohumol upregulates the Nrf2-HMOX1 antioxidative axis to inhibit PRRSV proliferation in PAMs}

Given that PAMs are natural target cells in pigs, we identified the role of $\mathrm{Xn}$ in PRRSV-infected PAMs. First, PAMs were treated with DMSO or 5,10 , and $15 \mu \mathrm{M}$ Xn for $1 \mathrm{~h}$ at $37^{\circ} \mathrm{C}$ and then infected with PRRSV (MOI 0.1) for $1 \mathrm{~h}$. Cells were washed and incubated in fresh culture medium containing 5, 10, and $15 \mu \mathrm{M}$ Xn for $24 \mathrm{~h}$. Virus was detected by virus titration. As shown in Figure 9A, $\mathrm{Xn}$ reduced the PRRSV titre in a dose-dependent manner in PAMs, which is consistent with the results in Marc-145 cells. Then, we sought to identify the correlation between $\mathrm{Xn}$ and the Nrf2-HMOX1 axis in PAMs. PAMs were treated with $10 \mu \mathrm{M}$ Xn for different times over $24 \mathrm{~h}$, followed by qRT-PCR for HMOX1 mRNA. Similar to in Marc-145 cells, HMOX1 mRNA was also induced by Xn in PAMs (Figure 9B). We also used different concentrations of CoPP to treat PAMs for $6 \mathrm{~h}$, then washed them 3 times and infected with PRRSV (MOI 0.01). At 48 hpi, the levels of viral $\mathrm{N}$-protein and HMOX1 in the cell lysates were examined by Western blotting. As expected, stimulating the expression of endogenous HMOX1 in PAMs significantly inhibited PRRSV replication in a dose-dependent manner (Figure 9C). Similarly, Xn induced HMOX1 and then inhibited PRRSV in a dose-manner in PAMs (Figure 9D).

To further explore the role of Nrf2 in this process, PAMs were treated with $\mathrm{Xn}(5,10$, and $15 \mu \mathrm{M})$ and showed a dose-dependent increase in Nrf2 and HMOX1 (Figure 9E). We next treated PAMs with $15 \mu \mathrm{M}$ Xn for $1 \mathrm{~h}$ and then infected them with PRRSV (MOI 0.01) for $1 \mathrm{~h}$. After washing the cells with PBS, culture medium containing Xn was added back. At $24 \mathrm{hpi}$, the cells were harvested for Western blotting. As shown in Figure 9F, PRRSV infection suppressed Nrf2 and HMOX1 expression, but $\mathrm{Xn}$ treatment resulted in increased Nrf2 and HMOX1 expression and inhibition of PRRSV 


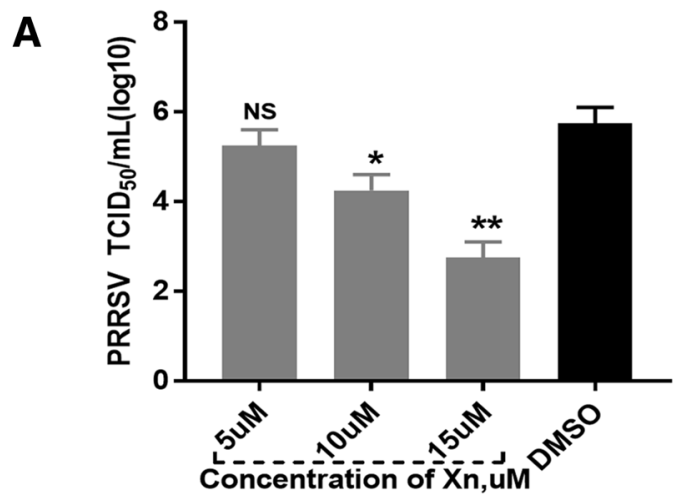

C

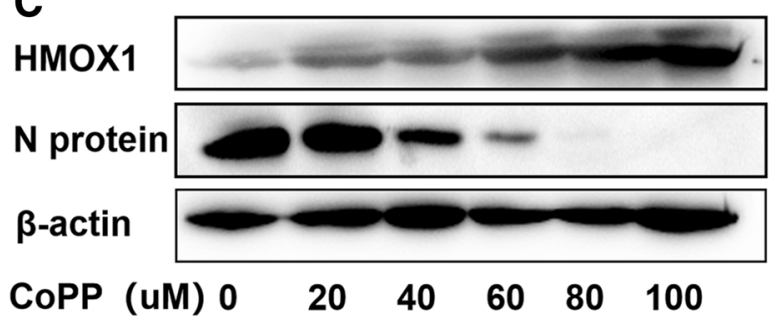

E

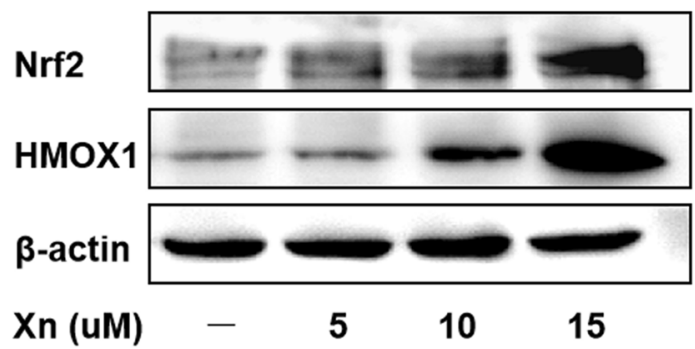

B

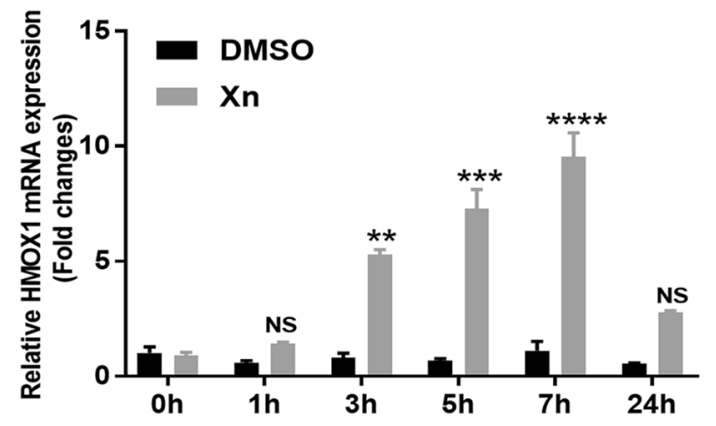

D

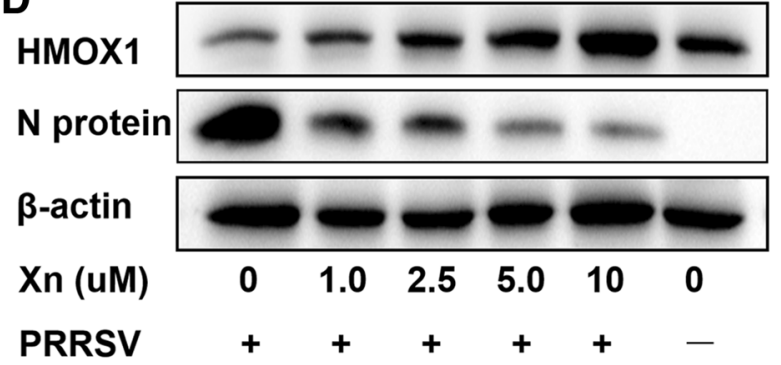

$F$

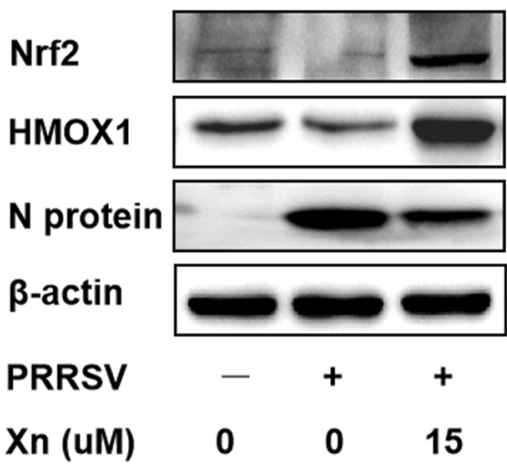

H

Nrf2

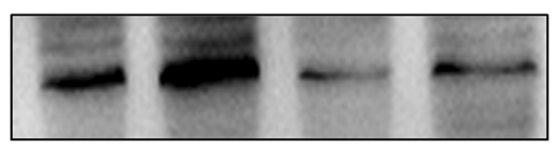

HMOX1

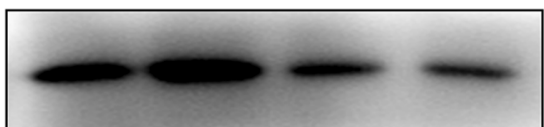

$\mathbf{N}$ protein

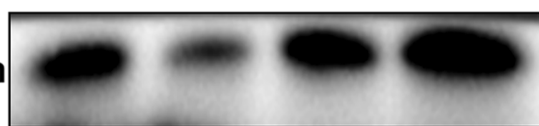

$\beta$-actin

PRRSV

siNrf2-a

si NC

Xn(10uM)

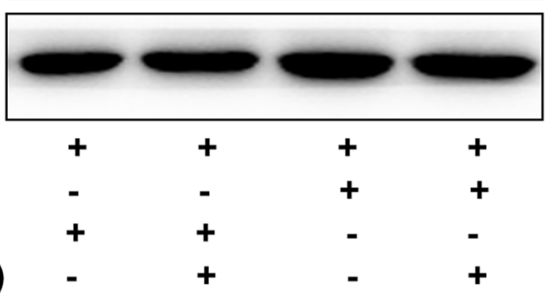




\begin{abstract}
(See figure on previous page.)
Figure 9 Xanthohumol upregulates the Nrf2-HMOX1 antioxidative axis to inhibit PRRSV proliferation in PAMs. A PAMs were pre-treated with DMSO or concentrations of $\mathrm{Xn}$ for $1 \mathrm{~h}$ and then infected with PRRSV $(0.10 \mathrm{MOI})$ for $1 \mathrm{~h}$ at $37^{\circ} \mathrm{C}$. Cells were washed and incubated in fresh medium containing DMSO or Xn. At 24 hpi, cells were harvested for the viral titre. B PAMs were treated with $10 \mu \mathrm{M}$ Xn for different times over $24 \mathrm{~h}$, followed by qRT-PCR for HMOX1 mRNA. ${ }^{* * *} P<0.001 ;{ }^{* *} P<0.01 ; * P<0.05$ vs DMSO-treated cells. C PAMs treated with CoPP (an inducer of HMOX1) for $6 \mathrm{~h}$ before PRRSV infection were examined for $\mathrm{N}$-protein and endogenous HMOX1 by Western blotting. D PAMs were treated with an increasing multiplicity of Xn (0-10 $\mu \mathrm{M}$ ) or DMSO for $1 \mathrm{~h}$ and then infected with PRRSV (MOI 0.01) for $1 \mathrm{~h}$. After washing three times with PBS, culture medium containing Xn (0-10 $\mu \mathrm{M})$ or DMSO was added back to the wells. At $24 \mathrm{hpi}$, the levels of HMOX1 and PRRSV N-protein were detected by Western blotting. E PAMs were treated with different doses of Xn for $24 \mathrm{~h}$, and Nrf2 and HMOX1 were detected by Western blotting. F PAMs were treated with $15 \mu \mathrm{M}$ Xn or DMSO for $1 \mathrm{~h}$ and then infected with PRRSV (MOI 0.01) for $1 \mathrm{~h}$. After washing three times with PBS, culture medium containing $15 \mu \mathrm{M}$ Xn or DMSO was added back to wells. At $24 \mathrm{hpi}$, the levels of Nrf2, HMOX1 and PRRSV N-protein were detected by Western blotting. G, H PAMs were transfected with 50 pmol of siRNA targeting Nrf2. After $48 \mathrm{~h}$, they were treated with $10 \mu \mathrm{M}$ Xn or DMSO for $1 \mathrm{~h}$ and then infected with PRRSV (0.01 MOI). After $36 \mathrm{hpi}$, the mRNA levels of Nrf2 and PRRSV ORF7 were detected by qRT-PCR (G). Meanwhile, the levels of Nrf2, HMOX1 and PRRSV N-protein were detected by Western blotting $(\mathbf{H}) .{ }^{* * *} P<0.001 ;{ }^{* *} P<0.01 ;{ }^{*} P<0.05$ compared with the control group
\end{abstract}

proliferation. Furthermore, Nrf2 expression knock-down also increased PRRSV replication in PAMs, and Xn had no inhibitory effect on PRRSV infection in PAMs transfected with the siRNA targeting Nrf2 (Figures 9G and H). These data support that the restrictive features of Xn on PRRSV replication depend on the Nrf2-HMOX1 axis.

Given that Xn could alleviate PRRSV-stimulated oxidative stress in Marc-145 cells, we also tested whether this effect occurred in PAMs. PAMs pre-treated with $12 \mu \mathrm{M}$ $\mathrm{H}_{2} \mathrm{O}_{2}$ for $3 \mathrm{~h}$ then incubated with $5 \mu \mathrm{M}$ Xn produced less ROS than untreated cells. FACS analysis also showed that in PAMs, PRRSV infection resulted in increased ROS levels and that Xn treatment reduced ROS levels (Figure 10A); the raw flow cytometry data are shown in Additional file 2. The reduction in SOD and GSH levels as a result of PRRSV infection was alleviated by Xn (Figures $10 \mathrm{~B}$ and $\mathrm{C}$ ). The elevated MDA levels in infected cells were reduced by Xn (Figure 10D).

\section{Discussion}

Natural products are a proven source of compounds for drug discovery, and the therapeutic use of plants has been known for millennia [28-30]. Natural compounds and compositions have also been a rich source for drugs against many viruses. Ouabain extracted from the seeds of Strophanthus gratus, bufalin isolated from the venom of the Bufo toad, and valinomycin extracted from Streptomyces fulvissimus can inhibit PRRSV replication at micromolar concentrations in Marc-145 cells [31]. Sodium tanshinone IIA sulfonate extracted from Salvia miltiorrhiza inactivates PRRSV directly, thereby inhibiting replication in vitro [16]. Glycyrrhizin extracted from liquorice root inhibits penetration of PRRSV but has little effect on viral adsorption or release in Marc-145 cells [32]. The mechanisms involved in these activities are not deeply understood. In this study, we screened a library of 386 natural products for anti-PRRSV activity. Xanthohumol significantly inhibited PRRSV proliferation in Marc-145 cells and PAMs and weakened PRRSVinduced oxidative stress by activating the Nrf2-HMOX1 pathway. It has promising therapeutic potential against PRRSV infection.

$\mathrm{Xn}$ is a prenylated flavonoid from the hop plant Humulus lupulus L [33]. Xn has anti-proliferative activity on breast, colon, and ovarian cancer cell lines [34]. Additionally, Xn has an anti-inflammatory effect on LPS-induced acute lung injury in mice [27], carbon tetrachloride-induced acute liver injury [35], and ischaemia reperfusion-induced liver injury [36]. Furthermore, Xn prevents cholesterol accumulation via CETP inhibition, leading to apoE upregulation in mice [37]. These research results demonstrate that $\mathrm{Xn}$ has a wide range of biological activities. We performed a transcriptome analysis of Xn-treated Marc-145 cells to initiate investigation into the mechanism of Xn inhibition of PRRSV. We found an enrichment of pathways associated with the Nrf2 antioxidant stress response; among them, HMOX1 was the most highly stimulated by Xn treatment. Haem oxygenase catabolizes haem and has three isoforms; HMOX1 is a rate-limiting enzyme in haem catabolism, leading to the generation of bilirubin, free iron, and carbon monoxide. HMOX1 is a stress response protein

\footnotetext{
(See figure on next page.)

Figure 10 Xanthohumol suppresses oxidative stress induced by PRRSV in PAMs. A ROS generation in PAMs was determined using flow cytometry. The frequency of the cells that tested FITC positive among the total cells is shown in the lower right corner of the image. The histogram was used to quantify the number of FITC-positive cells in two independent trials. B-D Effects of $10 \mu \mathrm{M}$ Xn on the levels of SOD, MDA, and GSH in PAMs infected with PRRSV or treated with $\mathrm{H}_{2} \mathrm{O}_{2}$. All results are means \pm standard deviations from three independent experiments performed in triplicate. ${ }^{\# \#} P<0.001 ;{ }^{\#} P<0.01 ;{ }^{\#} P<0.05$ vs $\mathrm{H}_{2} \mathrm{O}_{2}$-treated group. ${ }^{* *} P<0.001 ;{ }^{* *} P<0.01 ;{ }^{*} P<0.05$ vs PRRSV-infected cells
} 

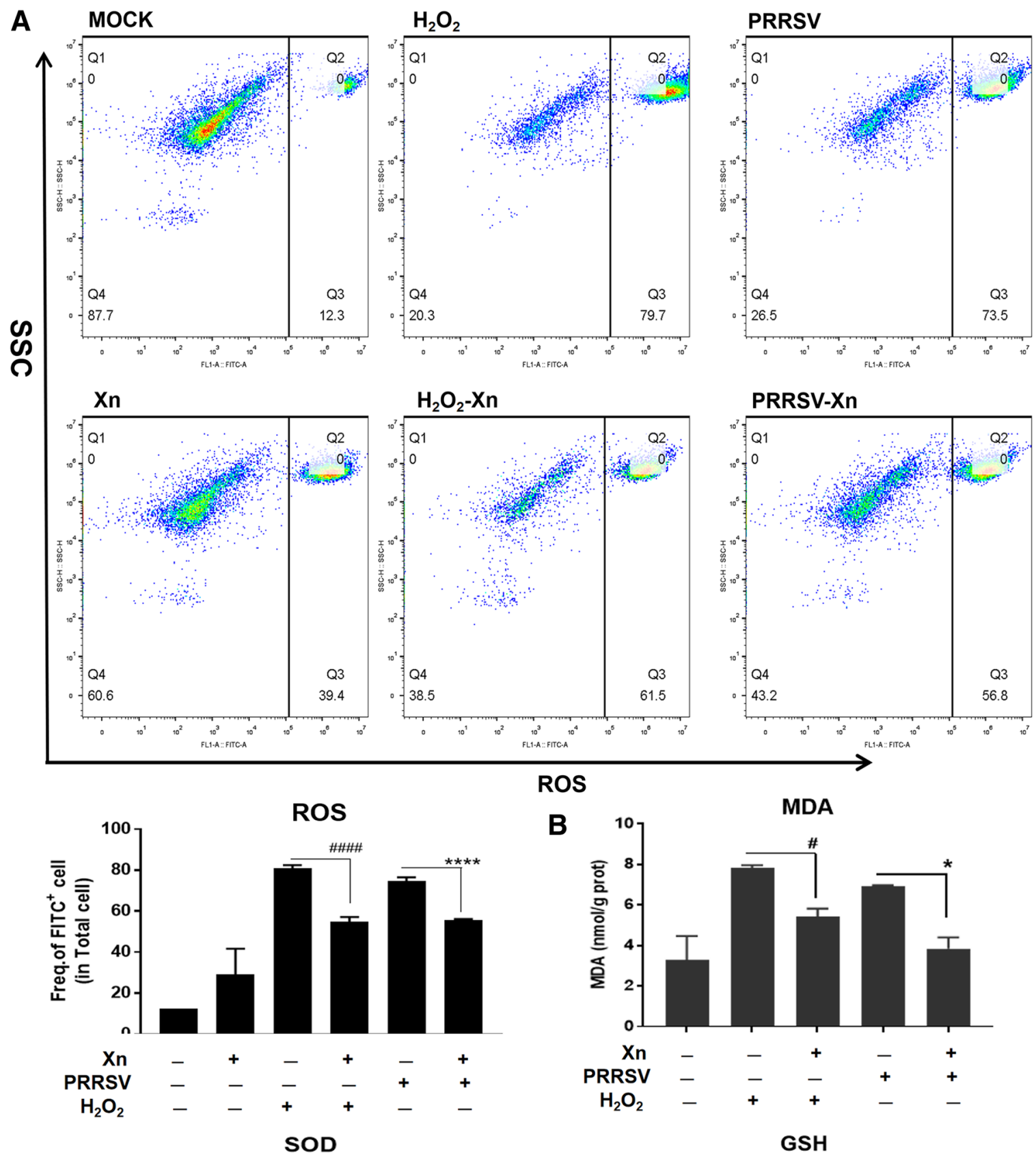

ROS

B

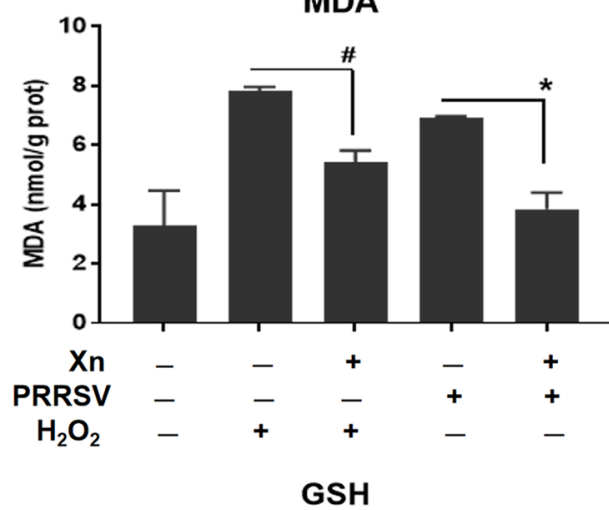

C

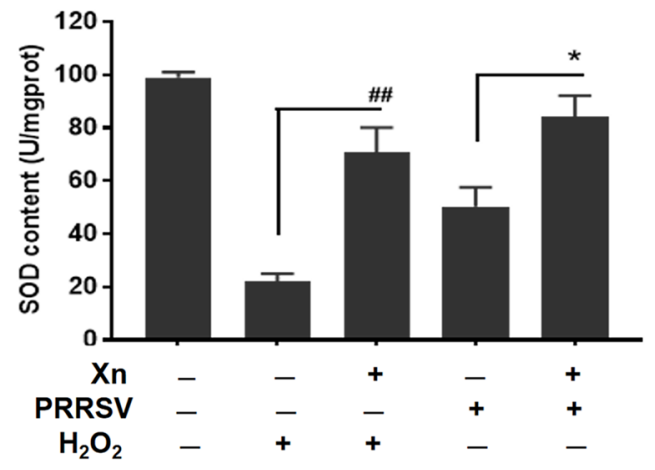

D

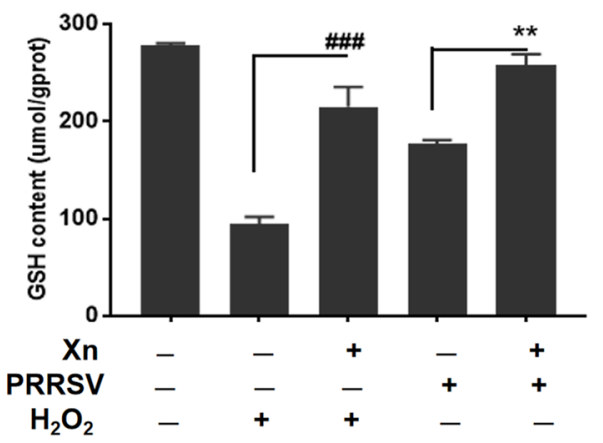




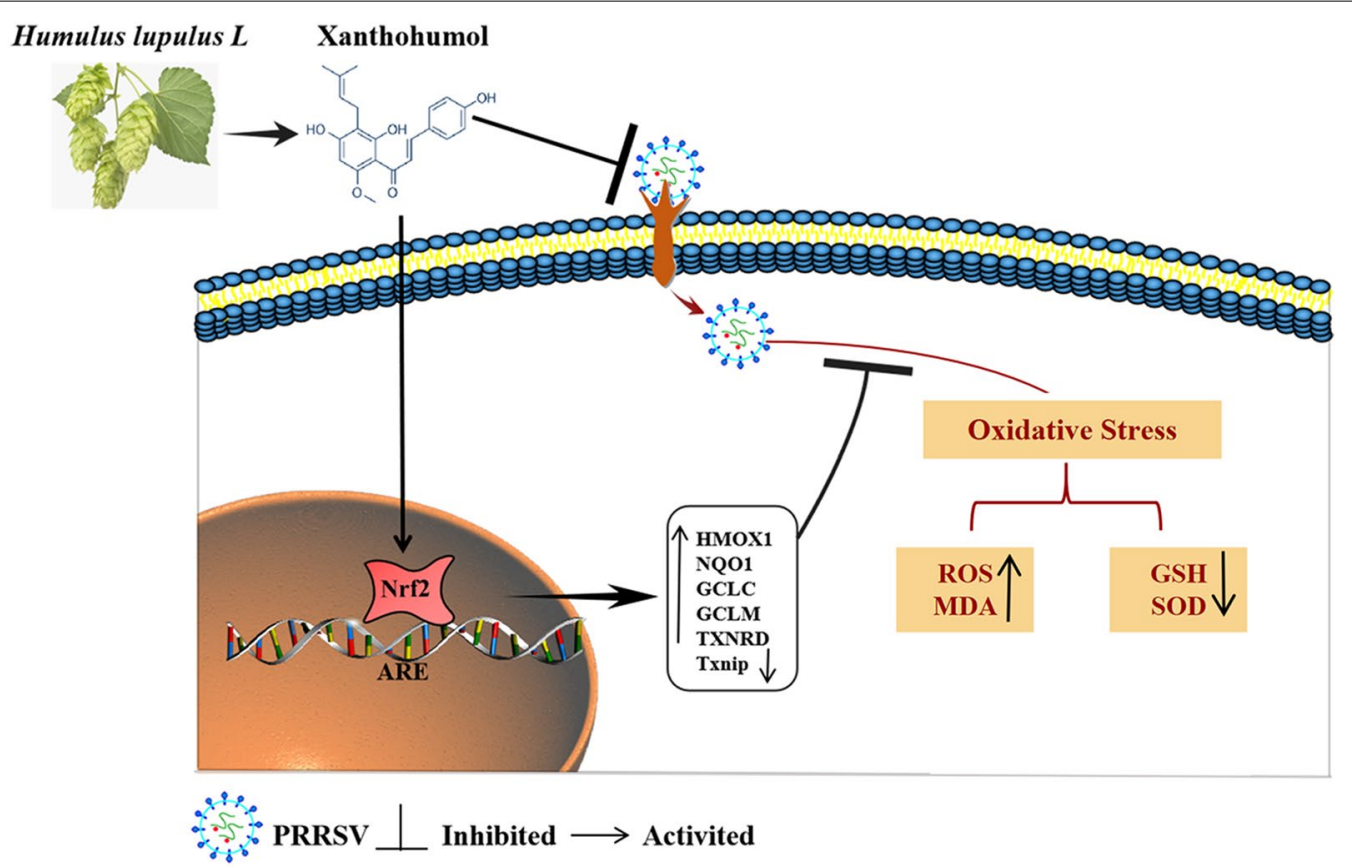

Figure 11 Scheme summarizing the inhibitory effect of xanthohumol on PRRSV proliferation via activation of the Nrf2-HMOX1 axis. Xanthohumol, a prenylated flavonoid found in hops, inhibits PRRSV adsorption onto and internalization into cells. Xn treatment also stimulates Nrf2, which causes an increase in the levels of the antioxidant enzymes HMOX1, GCLC, GCLM, and NQO1 and a suppression of oxidative stress, resulting in a decrease in virus proliferation

that can be induced by various oxidative agents through Nrf2-mediated transcriptional activation of AREs [38]. It can maintain redox homeostasis, cooperating with other antioxidant enzymes. HMOX1 has also been shown to have significant antiviral effects [39-41]. We found that Xn could induce the expression of HMOX1 in Marc-145 cells and PAMs in a dose-dependent manner. Overexpressed or induced HMOX1 attenuated PRRSV replication in Marc-145 and PAM cells. Nuclear factorerythroid 2-related factor $2(\mathrm{Nrf})$ is an essential factor in the cell's defence system, primarily regulating the expression of many genes involved in the oxidant response, such as HMOX1, NQO1, GCLC, and GCLM [42]. Transcriptional activation of these enzymes is through mainly binding of Nrf2 to antioxidant response elements (AREs) on their $5^{\prime}$ promoter $[43,44]$. The protective role of the Nrf2-ARE pathway has been examined in experimental models of various inflammatory and oxidative stressinduced respiratory diseases. For example, Nrf2 via the Nrf2-mediated signalling pathway limits oxidative stress and weakens the severity of allergic airway inflammation caused by asthma [45]. The importance of the Nrf2 pathway in viral pathogenesis was demonstrated in a study involving Nrf2 knockout mice. In that study, mice challenged with respiratory syncytial virus or influenza virus had elevated levels of viral replication and increased inflammatory responses and injury in their lungs [46]. Activation of the antioxidant pathways regulated by $\mathrm{Nrf} 2$ supports the regulation of antiviral and apoptotic responses by maintaining redox homeostasis in dengue virus-infected dendritic cells [47]. In this study, we found that Nrf2 had antiviral activity against PRRSV infection in Marc-145 cells and PAMs and that Xn directly targeted Nrf2 and stimulated the antioxidant pathways regulated by Nrf2. These results indicated that the Nrf2 antioxidant pathway plays a role in the anti-PRRSV activity of Xn. Nrf2 is a latent transcription factor present in an inactive form in the cytoplasm of cells as a complex with inhibitory proteins such as Keap1 (Kelch-like-associated protein1). Upon treatment with exogenous factors or induction of oxidative stress, $\mathrm{Nrf2}$ is activated via the disruption of this complex, allowing the subsequent translocation of active Nrf2 to the nucleus, where it binds to ARE sequences to activate transcription of relevant inducible genes [48]. This mechanism is a very important aspect of Nrf2 biology and the cellular response to oxidative stress. It should be determined whether translocation of Nrf2 from the cytoplasm to the nucleus of cells occurs upon PRRSV infection, Xn treatment or both. 
ROS generation is common in virus-infected cells. Cellular oxidative stress is significantly increased in dengue virus-infected dendritic cells [47]. Influenza virus infection increases reactive peroxynitrite formation and causes oxidative stress in lungs [49, 50], and PRRSV infection induces oxidative stress via ROS production in Marc-145 cells [51, 52]. The upregulation of ROS is related to mitochondrial dysfunction [52]. PRRSV downregulates the expression of superoxide dismutase, reduces that of glutathione, and increases the production of ROS and malondialdehyde in Marc-145 cells, PAMs, and the lung tissues of infected pigs. We found that Xn treatment effectively decreased PRRSV-induced oxidative stress. The Nrf2-mediated antioxidant response maintains an appropriate redox status and thus inhibits PRRSV-induced ROS damage.

The PRRSV life cycle can be divided into 4 basic stages: attachment, entry, replication and release [53, 54]. Our results showed that xanthohumol significantly inhibited PRRSV adsorption and entry in Marc-145 cells and PAMs. Numerous host cell-dependent factors can affect and control PRRSV attachment and uptake by (i) the level of a specific virus receptor, such as CD163; (ii) hostcell derived innate immune defence molecules aimed at binding and neutralizing the infectious virions; and (iii) antiviral mediators limiting viral replication [55]. Therefore, modification of any or several of these factors by Xn treatment could affect susceptibility to PRRSV infection. Here, our data demonstrated that siRNA-mediated knock-down of Nrf2 in MARC-145 cells increased PRRSV replication in these cells (Additional file 2). In addition, PRRSV infection induced oxidative stress. This result indicates that this virus-induced oxidative stress is beneficial for viral replication or that Nrf2 is involved in some way in the cellular innate antiviral response. In addition, we also noted that Xn downregulated the RNA expression of CD163, a key receptor of PRRSV [56] (Additional file 3). Nrf2 exists in most organs and affects the expression of nearly 500 proteins that act as redox balancing factors, detoxifying enzymes, stress response proteins and metabolic enzymes [57]. The changes in the cellular innate antiviral response, such as expression of RIG-I, IFN- $\beta$, and ISGs, and the receptor of PRRSV after treatment with $\mathrm{Xn}$ should be explored in the future.

In conclusion, (Figure 11), xanthohumol, a natural product derived from hops, effectively attenuated PRRSV proliferation and suppressed oxidative stress induced by PRRSV. These activities of Xn occurred largely via the activation of the Nrf2-HMOX1 pathway. This finding offers new and promising therapeutic possibilities for combating infections caused by PRRSV.

\section{Supplementary information}

Supplementary information accompanies this paper at https://doi. org/10.1186/s13567-019-0679-2.

Additional file 1. GO analysis of the top 100 DEGs according to log2 fold change at three time points. (A) GO analysis of the top 100 DEGs according to log2 fold change at $4 \mathrm{~h}$. (B) GO analysis of the top $100 \mathrm{DEGs}$ according to log 2 fold change at $8 \mathrm{~h}$. (C) GO analysis of the top 100 DEGs according to $\log 2$ fold change at $12 \mathrm{~h}$.

Additional file 2. Nrf2 knock-down blocked PRRSV entry. Marc-145 cells were transfected with 50 pmol of siNrf2 or siNC. After 24 h, CHX $(10 \mu \mathrm{g} / \mathrm{mL})$ was added and incubated for $12 \mathrm{~h}$, and then cells were incubated with PRRSV ( $1 \mathrm{MOI}$ ) for $1 \mathrm{~h}$ at $4^{\circ} \mathrm{C}$, washed, and incubated for another $1 \mathrm{~h}$ at $37^{\circ} \mathrm{C}$. The mRNA levels of PRRSV ORF7 and Nrf2 were detected by qRT-PCR. ${ }^{* *} P<0.01 ;{ }^{*} P<0.05$ vs siNC group.

Additional file 3. Xn treatment downregulated the CD163 mRNA levels in Marc-145 cells. (A) Heat map of expressed genes modulated by $10 \mu \mathrm{M}$ Xn or DMSO treatment in Marc-145 cells. Red and blue correspond to relative up- and downregulation, respectively. (B) Marc-145 cells were

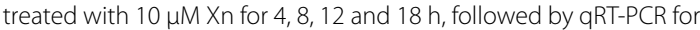
CD163 mRNA levels. ${ }^{* *} P<0.01 ;{ }^{*} P<0.05$ vs DMSO-treated cells.

\section{Acknowledgements}

The authors wish to thank Dr Xian-wei Wang for his generous help with the use of FlowJo and Dr Yu-feng Li for sharing his extensive knowledge of transcriptomics. In addition, the critical and helpful comments from the reviewers are highly appreciated.

\section{Authors' contributions}

Conceptualization: $X \mathrm{~L}, \mathrm{ZS}$, and PJ. Methodology: $\mathrm{XL}, \mathrm{ZS}, \mathrm{YZ}$, and PJ. Supervision: $J B$ and PJ. Performed the experiments: $X L$. Analysed the data: $X L, Z S, J B, Y Z$, and PJ. Writing — original draft: XL. Writing — review and editing: $X \mathrm{~L}, \mathrm{HN}$, and PJ. All authors read and approved the final manuscript.

\section{Funding}

This work was supported by the National Natural Science Foundation (Grant Number 31672565), the National Key Program of Research and Development of China (2018YFD0500803), the Jiangsu Key Program of Research and Development for PRRSV (BE2018386), a Grant from the Ministry of Agriculture for Swine Disease Control (Grant Number CARS-36), and the Priority Academic Program Development of Jiangsu Higher Education Institutions (PAPD).

\section{Competing interests}

The authors declare that they have no competing interests.

\section{Author details}

${ }^{1}$ Key Laboratory of Animal Disease Diagnostics and Immunology, Ministry of Agriculture, MOE International Joint Collaborative Research Laboratory for Animal Health \& Food Safety, College of Veterinary Medicine, Nanjing Agricultural University, Nanjing 210095, China. ${ }^{2}$ Laboratory of Virology, Faculty of Veterinary Medicine, Ghent University, Salisburylaan 133, 9820 Merelbeke, Belgium. ${ }^{3}$ Jiangsu Co-innovation Center for Prevention and Control of Important Animal Infectious Diseases and Zoonoses, Yangzhou, China.

Received: 31 March 2019 Accepted: 23 July 2019

Published online: 11 September 2019

\section{References}

1. Lunney JK, Benfield DA, Rowland RR (2010) Porcine reproductive and respiratory syndrome virus: an update on an emerging and re-emerging viral disease of swine. Virus Res 154:1-6

2. Neumann EJ, Kliebenstein JB, Johnson CD, Mabry JW, Bush EJ, Seitzinger AH, Green AL, Zimmerman JJ (2005) Assessment of the economic impact of porcine reproductive and respiratory syndrome on swine production in the United States. J Am Vet Med Assoc 227:385-392 
3. Nelsen CJ, Murtaugh MP, Faaberg KS (1999) Porcine reproductive and respiratory syndrome virus comparison: divergent evolution on two continents. J Virol 73:270-280

4. Tian K, Yu X, Zhao T, Feng Y, Cao Z, Wang C, Hu Y, Chen X, Hu D, Tian X, Liu D, Zhang S, Deng X, Ding Y, Yang L, Zhang Y, Xiao H, Qiao M, Wang B, Hou L, Wang X, Yang X, Kang L, Sun M, Jin P, Wang S, Kitamura Y, Yan J, Gao GF (2007) Emergence of fatal PRRSV variants: unparalleled outbreaks of atypical PRRS in China and molecular dissection of the unique hallmark. PLoS One 2:e526

5. Zhang Q, Bai J, Hou H, Song Z, Zhao Y, Jiang P (2017) A novel recombinant porcine reproductive and respiratory syndrome virus with significant variation in cell adaption and pathogenicity. Vet Microbiol 208:150-158

6. Murtaugh MP, Genzow M (2011) Immunological solutions for treatment and prevention of porcine reproductive and respiratory syndrome (PRRS). Vaccine 29:8192-8204

7. Renukaradhya GJ, Xiang-Jin M, Calvert JG, Michael R, Lager KM (2015) Inactivated and subunit vaccines against porcine reproductive and respiratory syndrome: current status and future direction. Vaccine 33:3065-3072

8. Fang J, Wang H, Bai J, Zhang Q, Li Y, Liu F, Jiang P (2016) Monkey viperin restricts porcine reproductive and respiratory syndrome virus replication. PLoS One 11:e156513

9. Wang H, Bai J, Fan B, Li Y, Zhang Q, Jiang P (2016) The interferon-induced $M \times 2$ inhibits porcine reproductive and respiratory syndrome virus replication. J Interferon Cytokine Res 36:129-139

10. Zhao J, Feng N, Li Z, Wang P, Qi Z, Liang W, Zhou X, Xu X, Liu B (2016) $2^{\prime}, 5^{\prime}$-Oligoadenylate synthetase 1(OAS1) inhibits PRRSV replication in Marc-145 cells. Antivir Res 132:268-273

11. Zhang L, Liu J, Bai J, Du Y, Wang X, Liu X, Jiang P (2013) Poly(l:C) inhibits porcine reproductive and respiratory syndrome virus replication in MARC-145 cells via activation of IFIT3. Antivir Res 99:197-206

12. Song Z, Zhang Q, Liu X, Bai J, Zhao Y, Wang X, Jiang P (2017) Cholesterol 25 -hydroxylase is an interferon-inducible factor that protects against porcine reproductive and respiratory syndrome virus infection. Vet Microbiol 210:153-161

13. Ke W, Fang L, Jing H, Tao R, Wang T, Li Y, Long S, Wang D, Xiao S (2017) Cholesterol 25-hydroxylase inhibits porcine reproductive and respiratory syndrome virus replication through enzyme activity dependent and independent mechanisms. J Virol 91:e00827-17

14. Xie J, Zhou H, Cui J, Chen Y, Zhang M, Deng S, Zhou P, Su S, Zhang G (2014) Inhibition of porcine reproductive and respiratory syndrome virus by specific siRNA targeting Nsp9 gene. Infect Genet Evol 28:64-70

15. Li L, Li Q, Bao Y, Li J, Chen Z, Yu X, Zhao Y, Tian K, Li N (2014) RNAi-based inhibition of porcine reproductive and respiratory syndrome virus replication in transgenic pigs. J Biotechnol 171:17-24

16. Sun N, Zhao X, Bai XY, Niu L, Song MQ, Sun YG, Jiang JB, Li HQ (2012) AntiPRRSV effect and mechanism of sodium tanshinone IIA sulfonate in vitro. $J$ Asian Nat Prod Res 14:721-728

17. Zhang M, Wu Q, Chen Y, Duan M, Tian G, Deng X, Sun Y, Zhou T, Zhang G, Chen W, Chen J (2018) Inhibition of proanthocyanidin A2 on porcine reproductive and respiratory syndrome virus replication in vitro. PLoS One 13:e193309

18. Li L, Tian X, Chen J, Li P, Zheng Q, Hou J (2018) Griffithsin inhibits porcine reproductive and respiratory syndrome virus infection in vitro. Arch Virol 163:3317-3325

19. Ge M, Xiao Y, Chen H, Luo F, Du G, Zeng F (2018) Multiple antiviral approaches of (-)-epigallocatechin-3-gallate (EGCG) against porcine reproductive and respiratory syndrome virus infection in vitro. Antivir Res 158:52-62

20. Chen X, Bai J, Liu X, Song Z, Zhang Q, Wang X, Jiang P (2018) Nspla of porcine reproductive and respiratory syndrome virus strain BB0907 impairs the function of monocyte-derived dendritic cells via the release of soluble CD83. JVirol 92:e00366-18

21. Krajka-Kuźniak V, Paluszczak J, Baer-Dubowska W (2013) Xanthohumol induces phase II enzymes via Nrf2 in human hepatocytes in vitro. Toxicol In Vitro 27:149-156

22. Cui B, Zhang S, Wang Y, Guo Y (2019) Farrerol attenuates $\beta$-amyloid-induced oxidative stress and inflammation through Nrf2/Keap1 pathway in a microglia cell line. Biomed Pharmacother 109:112-119
23. Li Y, Zhao Y, Cheng M, Qiao Y, Wang Y, Xiong W, Yue W (2018) Suppression of microRNA-144-3p attenuates oxygen-glucose deprivation/reoxygenationinduced neuronal injury by promoting Brg1/Nrf2/ARE signaling. J Biochem Mol Toxicol 32:e22044

24. Pae HO, Lee YC, Chung HT (2008) Heme oxygenase-1 and carbon monoxide: emerging therapeutic targets in inflammation and allergy. Recent Pat Inflamm Allergy Drug Discov 2:159-165

25. Dennery PA (2014) Signaling function of heme oxygenase proteins. Antioxid Redox Signal 20:1743-1753

26. Guo R, Davis D, Fang Y (2018) Intercellular transfer of mitochondria rescues virus-induced cell death but facilitates cell-to-cell spreading of porcine reproductive and respiratory syndrome virus. Virology 517:122-134

27. Lv H, Liu Q, Wen Z, Feng H, Deng X, Ci X (2017) Xanthohumol ameliorates lipopolysaccharide (LPS)-induced acute lung injury via induction of AMPK GSK3ß-Nrf2 signal axis. Redox Biol 12:311-324

28. Hossain MK, Choi HY, Hwang JS, Dayem AA, Kim JH, Kim YB, Poo H, Cho SG (2014) Antiviral activity of 3,4, dihydroxyflavone on influenza a virus. J Microbiol 52:521-526

29. Efferth T (2018) Beyond malaria: the inhibition of viruses by artemisinin-type compounds. Biotechnol Adv 36:1730-1737

30. Dias DA, Urban S, Roessner U (2012) A historical overview of natural products in drug discovery. Metabolites 2:303

31. Karuppannan AK, Wu KX, Qiang J, Chu JJ, Kwang J (2012) Natural compounds inhibiting the replication of Porcine reproductive and respiratory syndrome virus. Antivir Res 94:188-194

32. Duan E, Wang D, Fang L, Ma J, Luo J, Chen H, Li K, Xiao S (2015) Suppression of porcine reproductive and respiratory syndrome virus proliferation by glycyrrhizin. Antiviral Res 120:122-125

33. Sousa LRFD, Wu H, Nebo L, Fernandes JB, Kiefer W, Kanitz M, Bodem J, Diederich WE, Schirmeister T (2015) Flavonoids as noncompetitive inhibitors of Dengue virus NS2B-NS3 protease: inhibition kinetics and docking studies. Bioorgan Med Chem 23:466-470

34. Miranda CL, Stevens JF, Helmrich A, Henderson MC, Rodriguez RJ, Yang YH, Deinzer ML, Barnes DW, Buhler DR (1999) Antiproliferative and cytotoxic effects of prenylated flavonoids from hops (Humulus lupulus) in human cancer cell lines. Food Chem Toxicol 37:271-285

35. Pinto C, Duque AL, Rodrguez-Galden B, Cestero JJ, Macas P (2012) Xanthohumol prevents carbon tetrachloride-induced acute liver injury in rats. Food Chem Toxicol 50:3405-3412

36. Dorn C, Massinger S, Wuzik A, Heilmann J, Hellerbrand C (2013) Xanthohumol suppresses inflammatory response to warm ischemia-reperfusion induced liver injury. Exp Mol Pathol 94:10-16

37. Hirata H, Yimin Segawa S, Ozaki M, Kobayashi N, Shigyo T, Chiba H (2012) Xanthohumol prevents atherosclerosis by reducing arterial cholesterol content via CETP and apolipoprotein E in CETP-transgenic mice. PLoS One 7:e49415

38. Ryter SW, Choi AM (2002) Heme oxygenase-1: molecular mechanisms of gene expression in oxygen-related stress. Antioxid Redox Signal 4:625-632

39. Protzer U, Seyfried S, Quasdorff M, Sass G, Svorcova M, Webb D, Bohne F, HöSel M, Schirmacher P, Tiegs G (2007) Antiviral activity and hepatoprotection by heme oxygenase-1 in hepatitis B virus infection. Gastroenterology 133:1156-1165

40. Lehmann E, El-Tantawy WH, Ocker M, Bartenschlager R, Lohmann V, Hashemolhosseini S, Tiegs G, Sass G (2010) The heme oxygenase 1 product biliverdin interferes with hepatitis $C$ virus replication by increasing antiviral interferon response. Hepatology 51:398-404

41. Devadas K, Dhawan S (2006) Hemin activation ameliorates HIV-1 infection via heme oxygenase-1 induction. J Immunol 176:4252-4257

42. Suzuki T, Motohashi H, Yamamoto M (2013) Toward clinical application of the Keap1-Nrf2 pathway. Trends Pharmacol Sci 34:340-346

43. Mills EL, Ryan DG, Prag HA, Dikovskaya D, Menon D, Zaslona Z, Jedrychowski MP, Costa ASH, Higgins M, Hams E, Szpyt J, Runtsch MC, King MS, McGouran JF, Fischer R, Kessler BM, McGettrick AF, Hughes MM, Carroll RG, Booty LM, Knatko EV, Meakin PJ, Ashford ML, Modis LK, Brunori G, Sévin DC, Fallon PG, Caldwell ST, Kunji ERS, Chouchani ET et al (2018) Itaconate is an antiinflammatory metabolite that activates Nrf2 via alkylation of KEAP1. Nature 556:113-117

44. Krajka-Kuźniak V, Paluszczak J, Baer-Dubowska W (2017) The Nrf2-ARE signaling pathway: an update on its regulation and possible role in cancer prevention and treatment. Pharmacol Rep 69:393-402 
45. Rangasamy T, Guo J, Mitzner WA, Roman J, Singh A, Fryer AD, Yamamoto M, Kensler TW, Tuder RM, Georas SN, Biswal S (2005) Disruption of Nrf2 enhances susceptibility to severe airway inflammation and asthma in mice. J Exp Med 202:47-59

46. Cho H, Imani F, Miller-DeGraff L, Walters D, Melendi GA, Yamamoto M, Polack FP, Kleeberger SR (2009) Antiviral activity of Nrf2 in a murine model of respiratory syncytial virus disease. Am J Resp Crit Care 179:138-150

47. Olagnier D, Peri S, Steel C, van Montfoort N, Chiang C, Beljanski V, Slifker M, He Z, Nichols CN, Lin R, Balachandran S, Hiscott J (2014) Cellular oxidative stress response controls the antiviral and apoptotic programs in dengue virus-infected dendritic cells. PLoS Pathog 10:e1004566

48. Ge M, Yao W, Yuan D, Zhou S, Chen X, Zhang Y, Li H, Xia Z, Hei Z (2017) Brg1-mediated Nrf2/HO-1 pathway activation alleviates hepatic ischemiareperfusion injury. Cell Death Dis 8:e2841

49. Vlahos R, Stambas J, Selemidis S (2012) Suppressing production of reactive oxygen species (ROS) for influenza A virus therapy. Trends Pharmacol Sci 33:3-8

50. Choi AM, Knobil K, Otterbein SL, Eastman DA, Jacoby DB (1996) Oxidant stress responses in influenza virus pneumonia: gene expression and transcription factor activation. Am J Physiol 271:L383-391

51. Lee S, Kleiboeker SB (2005) Porcine arterivirus activates the NF-KB pathway through IKB degradation. Virology 342:47-59

52. Sang-Myeong L, Kleiboeker SB (2007) Porcine reproductive and respiratory syndrome virus induces apoptosis through a mitochondria-mediated pathway. Virology 365:419-434
53. Kappes MA, Faaberg KS (2015) PRRSV structure, replication and recombination: origin of phenotype and genotype diversity. Virology 479-480:475-486

54. Wang HM, Liu TX, Wang TY, Wang G, Liu YG, Liu SG, Tang YD, Cai XH (2018) Isobavachalcone inhibits post-entry stages of the porcine reproductive and respiratory syndrome virus life cycle. Arch Virol 163:1263-1270

55. Wang R, Wang X, Ni B, Huan CC, Wu JQ, Wen LB, Liao Y, Tong GZ, Ding C, Fan HJ, Mao X (2016) Syndecan-4, a PRRSV attachment factor, mediates PRRSV entry through its interaction with EGFR. Biochem Biophys Res Commun 475:230-237

56. Burkard C, Lillico SG, Reid E, Jackson B, Mileham AJ, Ait-Ali T, Whitelaw CBA, Archibald AL (2017) Precision engineering for PRRSV resistance in pigs: macrophages from genome edited pigs lacking CD163 SRCR56 domain are fully resistant to both PRRSV genotypes while maintaining biological function. PLoS Pathog 13:e1006206

57. Liu T, Liu M, Liu S, Chen F, Chen F, Yang J (2017) The role of oxidative stress in influenza virus infection. Microbes Infect 19:580-586

\section{Publisher's Note}

Springer Nature remains neutral with regard to jurisdictional claims in published maps and institutional affiliations.
Ready to submit your research? Choose BMC and benefit from:

- fast, convenient online submission

- thorough peer review by experienced researchers in your field

- rapid publication on acceptance

- support for research data, including large and complex data types

- gold Open Access which fosters wider collaboration and increased citations

- maximum visibility for your research: over $100 \mathrm{M}$ website views per year

At BMC, research is always in progress.

Learn more biomedcentral.com/submissions 